\title{
Transcriptome Analysis of Bombyx mori Larval Midgut during Persistent and Pathogenic Cytoplasmic Polyhedrosis Virus Infection
}

\author{
Anna Kolliopoulou ${ }^{1}$, Filip Van Nieuwerburgh ${ }^{2}$, Dimitrios J. Stravopodis ${ }^{3}$, Dieter Deforce ${ }^{2}$, \\ Luc Swevers $^{1 *}$, Guy Smagghe ${ }^{4 *}$ \\ 1 Insect Molecular Genetics and Biotechnology, Institute of Biosciences and Applications, National Centre \\ for Scientific Research "Demokritos", Aghia Paraskevi, Athens, Greece, 2 Laboratory of Pharmaceutical \\ Biotechnology, Department of Pharmaceutics, Faculty of Pharmaceutical Sciences, Ghent University, Ghent, \\ Belgium, 3 Department of Cell Biology and Biophysics, Faculty of Biology, University of Athens, Athens, \\ Greece, 4 Laboratory of Agrozoology, Department of Crop Protection, Faculty of Bioscience Engineering, \\ Ghent University, Ghent, Belgium \\ * swevers@bio.demokritos.gr (LS); guy.smagghe@ugent.be (GS)
}

\section{G open Access}

Citation: Kolliopoulou A, Van Nieuwerburgh F, Stravopodis DJ, Deforce D, Swevers L, Smagghe G (2015) Transcriptome Analysis of Bombyx mori Larval Midgut during Persistent and Pathogenic Cytoplasmic Polyhedrosis Virus Infection. PLoS ONE 10(3): e0121447. doi:10.1371/journal.pone.0121447

Academic Editor: Alexander W. E. Franz, University of Missouri, UNITED STATES

Received: June 11, 2014

Accepted: February 12, 2015

Published: March 27, 2015

Copyright: @ 2015 Kolliopoulou et al. This is an open access article distributed under the terms of the Creative Commons Attribution License, which permits unrestricted use, distribution, and reproduction in any medium, provided the original author and source are credited.

Data Availability Statement: All sequence files from the mRNA and small RNA libraries are available from the European Nucleotide Archive database (accession number PRJEB7502). All other relevant data are within the paper and its Supporting Information files.

Funding: The authors acknowledge support by the Research Council of Ghent University (BOF-UGent, Belgium) (www.ugent.be, Belgium), the Fund for Scientific Research-Flanders (FWO-Vlaanderen, Belgium) (www.fwo.be), and the General Secretariat for Research and Technology, Hellenic Republic

\section{Abstract}

Many insects can be persistently infected with viruses but do not show any obvious adverse effects with respect to physiology, development or reproduction. Here, Bombyx mori strain Daizo, persistently infected with cytoplasmic polyhedrosis virus (BmCPV), was used to study the host's transcriptional response after pathogenic infection with the same virus in midgut tissue of larvae persistently and pathogenically infected as 2 nd and 4 th instars. Next generation sequencing revealed that from 13,769 expressed genes, 167 were upregulated and 141 downregulated in both larval instars following pathogenic infection. Several genes that could possibly be involved in $B$. mori immune response against $B m C P V$ or that may be induced by the virus in order to increase infectivity were identified, whereas classification of differentially expressed transcripts (confirmed by qRT-PCR) resulted in gene categories related to physical barriers, immune responses, proteolytic / metabolic enzymes, heat-shock proteins, hormonal signaling and uncharacterized proteins. Comparison of our data with the available literature (pathogenic infection of persistently vs. non-persistently infected larvae) unveiled various similarities of response in both cases, which suggests that pre-existing persistent infection does not affect in a major way the transcriptome response against pathogenic infection. To investigate the possible host's RNAi response against BmCPV challenge, the differential expression of RNAi-related genes and the accumulation of viral small RNAs (vsRNAs) were studied. During pathogenic infection, siRNA-like traces like the 2-fold up-regulation of the core RNAi genes Ago-2 and Dcr-2 as well as a peak of $20 \mathrm{nt}$ small RNAs were observed. Interestingly, vsRNAs of the same size were detected at lower rates in persistently infected larvae. Collectively, our data provide an initial assessment of the relative significance of persistent infection of silkworm larvae on the host response following 
Ministry of National Education and Religious Affairs, in Greece (www.gsrt.gr). Anna Kolliopoulou is a recipient of a PhD fellowship from NCSR "Demokritos". The funders had no role in study design, data collection and analysis, decision to publish, or preparation of the manuscript.

Competing Interests: The author GS of the submitting paper is editor for PLOS ONE and this does not alter the author's adherence to all the PLOS ONE policies on sharing data and materials. pathogenic infection with CPV, while they also highlight the relative importance of RNAi as an antiviral mechanism.

\section{Introduction}

Interest in viruses originates mainly from their role as pathogens that can cause significant disease in hosts. Regarding pathogenic infections in insects, virus research focuses on the protection of beneficial insects such as the honeybee, Apis mellifera, and the silkworm, Bombyx mori, against virus infection $[1,2]$ as well as on the improvement of the use of viruses to control agricultural pests [3]. In addition, many research activities focus on the transmission by mosquitoes of arbovirus infections that cause disease in humans and livestock $[4,5]$.

With the advent of next generation sequencing technologies, however, it has been realized that many insect species can be persistently infected with viruses that do not cause an obvious adverse symptom or abnormal phenotype $[6,7]$. In contrast to acute infections, which are limited in time, resulting either in clearance of the virus or death of the host, persistent infections can be maintained in the hosts for very long periods and transmitted to the offspring [8]. With time, mutualistic relationships can even be developed between host and virus and, in some cases, it has been documented that viral genes and mechanisms are adopted by the host for its own benefit, for instance in the immune response [9]. Of great interest are also arbovirus infections in mosquito vectors, which can be considered as persistent infections where both mosquito vector and virus need to survive for a sufficient time to allow transmission to the vertebrate link in the infection cycle [10]. Also honeybee populations can be persistently infected with multiple viruses without affecting the health of the colony [11]. However, bee viruses are often mentioned as one of the multifactorial causes of the decline of honeybee colonies [12] and it can therefore be hypothesized that persistent infections could turn pathogenic in conditions of increased stress. Because of their prevalence, persistent infections deserve more attention with respect to alterations in the physiology of the host, such as the immune response, and to conditions that could turn apparently harmless persistent infections into disease.

B. mori cytoplasmic polyhedrosis virus (BmCPV), a reovirus characterized by a segmented dsRNA genome, is a major pathogen of the silkworm [13]. In contrast to baculovirus infections, which can spread efficiently throughout the body and are very virulent to the host, CPV infections are mostly or exclusively limited to the midgut tissue, cause less damage and therefore have a propensity to become persistent [14]. During our research with BmCPV, it was noticed that our laboratory strain of silkworm, Daizo, was persistently infected with BmCPV. Despite the infection, however, animals appeared healthy, showed normal growth and metamorphosis, and produced batches of fertilized eggs of typical size. Because of this observation, we considered the persistently infected silkworm strain as an interesting experimental model to investigate the (alteration of the) transcriptional response after feeding of a high dose of BmCPV polyhedra that caused clear pathogenic effects. Several studies concerning the transcriptional responses to BmCPV infection can be found in literature; however, these responses were recorded in larvae for which no persistent infection was reported [15-18]. Another study was focused on the miRNAs' differential expression during BmCPV infection [19].

In our study, deep sequencing (Illumina) technology was applied to obtain an initial assessment of the transcriptional response in silkworm larvae that were persistently or pathogenically infected with BmCPV. Instead of having different biological replicates at a single developmental stage, it was decided in this explorative study to compare the transcriptional responses 
between persistently and pathogenically infected animals at two different developmental stages $\left(2^{\text {nd }}\right.$ and $4^{\text {th }}$ larval instars) and to focus on genes that become differentially expressed irrespective of the developmental stage. The identification of differentially expressed genes was subsequently validated by qRT-PCR experiments on samples obtained from $2^{\text {nd }}$ instar larvae. Despite the limitation of the deep sequencing analysis (data from four unique samples, corresponding to persistent or pathogenic infection in the $2^{\text {nd }}$ or $4^{\text {th }}$ instar), it is believed that valuable preliminary data were obtained that will stimulate further research. It is noted that a similar format of experimental design was applied to the study of differentially expressed microRNAs (miRNAs) after BmCPV infection [19].

Our study establishes a considerable overlap in the transcriptional response to BmCPV during a pathogenic infection of persistently infected silkworm larvae with the transcriptional response documented in the above mentioned studies where no persistent infection was reported. In addition, we focused on the involvement of the RNA interference (RNAi) machinery during BmCPV infection, which has not received much attention in previous BmCPV-related studies. Although RNAi has been considered as the most important antiviral response in Drosophila and mosquitoes [20-22], in insects of other groups, such as the honeybee or the silkworm, its involvement in antiviral defense remains largely unknown. Attention is therefore paid to the transcriptional response of RNAi machinery genes during a pathogenic BmCPV infection as well as to the detection of virus-derived small RNAs (vsRNAs).

\section{Materials and Methods}

\section{Silkworm rearing and infection with BmCPV}

The larvae of B. mori, Daizo strain, were reared on artificial diet (Yakuruto, Tokyo, Japan) at $25^{\circ} \mathrm{C}$ under a photoperiod of $12 \mathrm{~h}$ light and $12 \mathrm{~h}$ dark. For pathogenic infection with BmCPV, aliquots of artificial diet were treated with $50 \mu \mathrm{l}$ of a concentrated solution of polyhedra of $\operatorname{BmCPV}\left(3.25 \times 10^{7}\right.$ polyhedra $\left./ \mathrm{ml}\right)$ and fed to $2^{\text {nd }}$ instar $(\mathrm{N}=30)$ or $4^{\text {th }}$ instar larvae $(\mathrm{N}=30)$, 1-2 days after molt. Successful pathogenic infection was indicated by retardation of growth and confirmed by detection of polyhedra by means of optical microscopy as well as by genespecific RT-PCR for polyhedrin (see Results and Discussion section). Midgut and body wall tissue was collected from pathogenically infected larvae at 10-20 days after feeding of BmCPV polyhedra. The same tissues were also collected from control (persistently infected) larvae at a similar stage.

\section{RNA extraction and reverse-transcription PCR (RT-PCR)}

Tissues were homogenized in TRI Reagent (Sigma, Saint Louis, MO) and total RNA was extracted according to the manufacturer's protocol. The quantity of extracted RNA was assessed with a NanoDrop 1000 Spectrophotometer (Thermo Scientific, Waltham, MA) and/or by electrophoresis on $1 \%(\mathrm{w} / \mathrm{v})$ agarose gels. RNA for specific detection of BmCPV polyhedrin was first mixed with DMSO at 1:1 ratio and heated at $50^{\circ} \mathrm{C}$ for 45 minutes for denaturation of dsRNA BmCPV genome. One microgram of total RNA was used as template for first-strand complementary DNA (cDNA) synthesis as performed by a Revert Aid reverse transcriptase (Thermo Scientific). Random hexamers (Thermo Scientific) were utilized as primers for cDNA templates of quantitative RT-PCR, whereas BmCPV segment 10-specific primer 5'-AGGATCATGGCAGACGTAGC-3' was used to synthesize cDNA templates for polyhedrin-specific RT-PCR. Viral polyhedrin was detected using the same RT primer as forward primer and 5'TAGGCGTTCGGCGAAATGT-3' as reverse primer, under the following cycling conditions: $94^{\circ} \mathrm{C}$ for $30 \mathrm{~s}, 50^{\circ} \mathrm{C}$ for $30 \mathrm{~s}$ and $72^{\circ} \mathrm{C}$ for $45 \mathrm{~s}$ ( 40 cycles). 


\section{Deep sequencing of RNA samples from midguts of pathogenically and persistently infected larvae}

The four RNA samples that were prepared for deep sequencing analysis were derived from midgut tissue of persistently ("control") and pathogenically infected $2^{\text {nd }}$ instar larvae (2c and 2 inf), as well as of persistently ("control") and pathogenically infected $4^{\text {th }}$ instar larvae (4c and 4inf). RNA quantifications were performed using Qubit fluorometry (Life technologies, Carlsbad, CA).

For each sample, an Illumina mRNA sequencing library was made from $100 \mathrm{ng}$ of total RNA using the TruSeq Stranded mRNA Sample Prep Kit (Illumina, San Diego, CA), whereas approximately $500 \mathrm{ng}$ of total RNA was used to create a small RNA library using the TruSeq Small RNA Sample Preparation Kit (Illumina). The 4 mRNA and the 4 small RNA libraries were each equimolarly pooled and sequenced in one lane of an Illumina HiSeq 2000 flowcell, generating 1 x 50 bp reads. After sequencing, the data was demultiplexed using the sample specific nucleotide barcodes. On average, $30 \times 10^{6}$ mRNAs were generated. The mRNA and small RNA differential expression analysis was performed using CLC bio (Qiagen, Venlo, The Netherlands). All reads were trimmed for Illumina adapter sequences.

The mRNA reads were mapped to the Bombyx annotated genome (Kaikobase: http://sgp. dna.affrc.go.jp/pubdata/genomicsequences.html) [23]. For the 2inf, 2c, 4inf and 4c mRNA samples, the percentage of mapped reads was $24 \%, 37 \%, 29 \%$ and $36 \%$, respectively. The lower percentages of reads that were mapped in the infected samples likely reflect the predominance of transcripts that could be mapped to the viral genome, which illustrates the severity of the infection in those samples. The number of mRNA reads that mapped to a transcript was divided by the transcript length and normalized per sample by the number of mapped reads to calculate the RPKM (Reads Per Kilobase per Million mapped reads) expression values for each gene, thus making possible the direct comparison of differential expression among samples [24, 25]. Because of the lack of biological repeats, we did not use $\mathrm{T}$ statistics to identify significant differentially expressed genes. Instead, we filtered the RNA-seq data according to the following criteria: (i) total gene reads count resulting from all 4 libraries should be more than 10, and (ii) selected transcripts should present at least a 2 -fold RPKM change $(\mid \log 2$ Ratio $\mid \geq 1)$ between pathogenically and persistently infected in both library pairs (2inf/2c, 4inf/4c) towards the same direction, i.e. up- or down-regulation [26, 27]. These criteria therefore ensure, first, that all relevant genes including those with low, but significant, expression level are evaluated, and, second, that a significant change in expression occurs that is independent of the developmental stage of the infected larvae.

Regarding small RNAs, after trimming, more than $95 \%$ of the original number of reads was used for small RNA tag counting. Approximately $15 \%$ of the tags had a count lower than 5 and these were discarded. The remaining tags were counted and annotated using the Bombyx miRNA miRBASE 19 database. The small RNAs that did not map against the Bombyx miRNA miRBASE 19 database were subsequently mapped against the BmCPV genome to find vsRNAs originating from the virus. Small RNA length distribution graphs were produced in R [28] by use of the viRome package (http://www.ark-genomics.org/bioinformatics/virome). The sequences from the mRNA and small RNA libraries of all 4 samples were submitted to the European Nucleotide Archive (Accession Number PRJEB7502).

\section{Gene Ontology (GO) analysis}

A list of sequences that were identified as differentially expressed between persistently and pathogenically infected larvae (see Results and Discussion section) were analyzed for GO annotation [http://www.geneontology.org [29]]. Sequences were identified based on the annotated 
gene set at Kaikobase and genes resulting from the homology searches were used as input in DAVID [http://david.abcc.ncifcrf.gov [30]].

\section{Real-time quantitative RT-PCR}

Real-time qRT-PCR was performed in a Mx3000P QPCR System (Agilent Technologies, Santa Clara, CA) equipped with MxPro QPCR Software (Agilent Technologies) using KAPA SYBR FAST qPCR Kit (Kapa Biosystems, Wilmington, MA), gene-specific primers at a final concentration of $0.55 \mu \mathrm{M}$ each and $12.5 \mathrm{ng}$ of midgut cDNA template. Relative transcript levels were normalized to the expression level of the cellular actin gene. PCR cycling started with initial activation of KAPA SYBR FAST Master Mix polymerase at $95^{\circ} \mathrm{C}$ for $3 \mathrm{~min}$, followed by 40 cycles of $95^{\circ} \mathrm{C}$ for $5 \mathrm{~s}, 59$ or $60^{\circ} \mathrm{C}$ for $30 \mathrm{~s}$ and $72^{\circ} \mathrm{C}$ for $5 \mathrm{~s}$. Forward and reverse primers to detect specific transcripts ( $\mathrm{S} 1 \mathrm{Table}$ ) were designed using Primer Express 2.0 software (Applied Biosystems/ Life Technologies). Relative expression levels of target gene (X) were calculated in relation to the transcription levels of the actin reference gene (R), as $2^{-\Delta C t}$, where $\Delta C_{t}=C_{t}{ }^{X}-C_{t}{ }^{R}$.

\section{Results and Discussion}

\section{Persistent (non-pathogenic) infection of silkworm with BmCPV}

To verify infection of silkworm larvae with BmCPV, we performed RT-PCR with gene-specific primers for the viral polyhedrin gene. The samples tested corresponded to RNA collected from body wall, midgut, midgut content and feces. For pathogenic infections (2inf and 4inf samples), polyhedrin product was detected at high levels in all samples analyzed (midgut tissue, midgut content, feces and body wall; Fig. 1). However, rather high amounts of polyhedrin RNA could also be detected in the midgut content of the control (not pathogenically infected) $2^{\text {nd }}$ instar larvae (2c sample) and low levels were also present in the midgut tissue (both $2^{\text {nd }}$ and $4^{\text {th }}$ instar stages; Fig. 1). In addition, cDNA samples derived from the eggs of the same strain as the larvae (Daizo) were also positive for polyhedrin RNA, in contrast to the eggs of the P50 strain, which gave no PCR product (Fig. 1). PCR products obtained from control midguts ( $4^{\text {th }}$ instar) and

(a)

\begin{tabular}{|c|c|c|c|c|c|c|c|c|}
\hline \multicolumn{4}{|c|}{$2 c$} & \multicolumn{4}{|c|}{ 2inf } & \multirow[t]{2}{*}{$(-)$} \\
\hline BW & MG & MGC & $\mathbf{F}$ & BW & MG & MGC & $F$ & \\
\hline
\end{tabular}

(b)

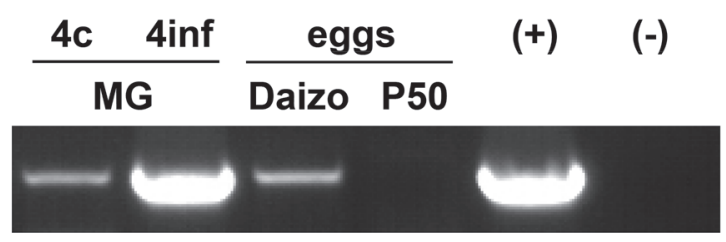

Fig 1. Detection of BmCPV polyhedrin by RT-PCR in persistently and pathogenically infected silkworm tissues and eggs. Polyhedrin RT-PCR was performed using samples derived from larvae persistently and pathogenically infected (a) at the $2^{\text {nd }}$ or (b) the $4^{\text {th }}$ instar (2c, 2 inf, $4 \mathrm{c}$ and $4 \mathrm{inf}$ samples), as well as from Daizo and P50 silkworm strain-derived eggs. Polyhedrin PCR product with a size of 689 nucleotides was obtained after 40 cycles of PCR. Abbreviations: BW: body wall, MG: midgut, MGC: midgut content, F: feces, (+): positive control (BmCPV polyhedra), (-): negative control (water sample).

doi:10.1371/journal.pone.0121447.g001 
Daizo eggs were validated by sequencing to correspond to BmCPV polyhedrin. The detection of polyhedrin RNA in midgut tissue and eggs of animals of the Daizo strain in our colony is indicative of a persistent state of infection by BmCPV.

Thus, larvae of the Daizo strain that were pathogenically infected in our study with BmCPV were already persistently infected with the same virus at low levels. This persistent state of infection was not visibly correlated with pathogenic effects, as larvae apparently grew, molted and metamorphosed normally. It should also be mentioned that polyhedra were never detected in any control animal under normal rearing following microscope observation. Furthermore, RT-PCR experiments revealed the presence of polyhedrin RNA mainly in the midgut content of control larvae and only traces in the midgut tissue itself (Fig. 1), which suggests that in persistently infected larvae, the infection of the midgut tissue (epithelium and associated muscle and connective tissue) is efficiently cleared, thus preventing the occurrence of pathogenic defects. This contrasts to the situation in pathogenically infected larvae, where high amounts of polyhedrin RNA were detected in the midgut tissue (Fig. 1), being indicative of high levels of viral replication/production (see further below). Finally, virus-derived small RNAs (vsRNAs) were detected in both persistently and pathogenically infected larvae (Fig. 2; see also Detection and preliminary analysis of $v$ sRAs paragraph); however, the detection levels in the control larvae were minimal, further corroborating the low levels of viral RNA in persistently infected tissues.

\section{Oral infection of silkworm larvae with BmCPV polyhedra}

Persistently infected larvae of Daizo strain were pathogenically infected through the oral route with $5.5 \times 10^{4}$ polyhedra per larva. At the time of infection, the larvae were at the beginning of the $2^{\text {nd }}$ or the $4^{\text {th }}$ instar developmental stage. The infection was verified macroscopically by observation of the infected larvae (S1 Fig.), as well as microscopically by detection of viral polyhedra in the larval midgut tissue (S2 Fig.). As shown for a representative group of persistently and pathogenically infected larvae in S1 Fig., the sizes of the pathogenically infected larvae varied notably among several individuals. This phenomenon was observed in both $2^{\text {nd }}$ and $4^{\text {th }}$ instar infected larvae. However, polyhedra could be detected in larvae of all sizes, indicating that the impact of the infection on body size did not correlate with the presence of infection.

According to the literature, BmCPV targets epithelial midgut cells and is not expected to expand all over the larval body. Nevertheless, following observation of several larval organs under the microscope, we have detected polyhedra also in the interior of the body wall, as well as in the hemolymph (S2 Fig.).

\section{Transcriptome analysis of larval midgut samples}

RNA-seq was used to analyze midgut samples from silkworm larvae infected in the $2^{\text {nd }}$ and $4^{\text {th }}$ instar stage, in order to detect differentially expressed transcripts during persistent and pathogenic BmCPV infection. Deep sequencing was carried out on samples from two different developmental stages to identify transcripts that are differentially expressed irrespective of the developmental stage, instead of having biological replicates at the same stage of development. Transcriptome analysis resulted in the identification of 13,769 expressed genes over all 4 RNA samples (S1 Dataset). Filtering of RNA-seq data according to the criteria outlined in Materials and Methods section resulted in 167 up-regulated and 141 down-regulated transcripts in both instars (Fig. 3; S2 and S3 Datasets).

According to GO analysis of the 308 differentially expressed transcripts, 201 were found to have a GO annotation and were initially categorized in the three main GO functional groups, 
persistent infection

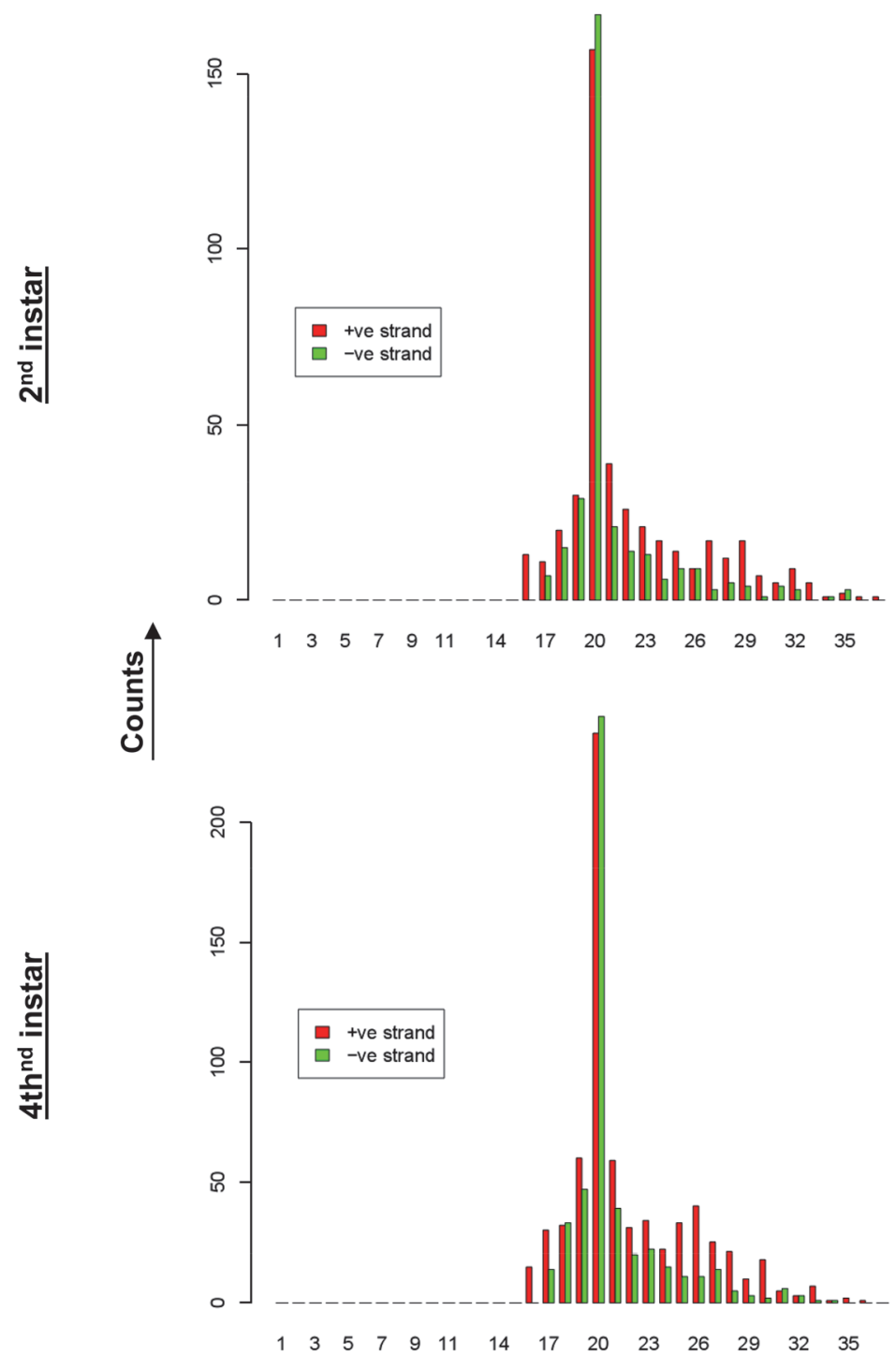

pathogenic infection
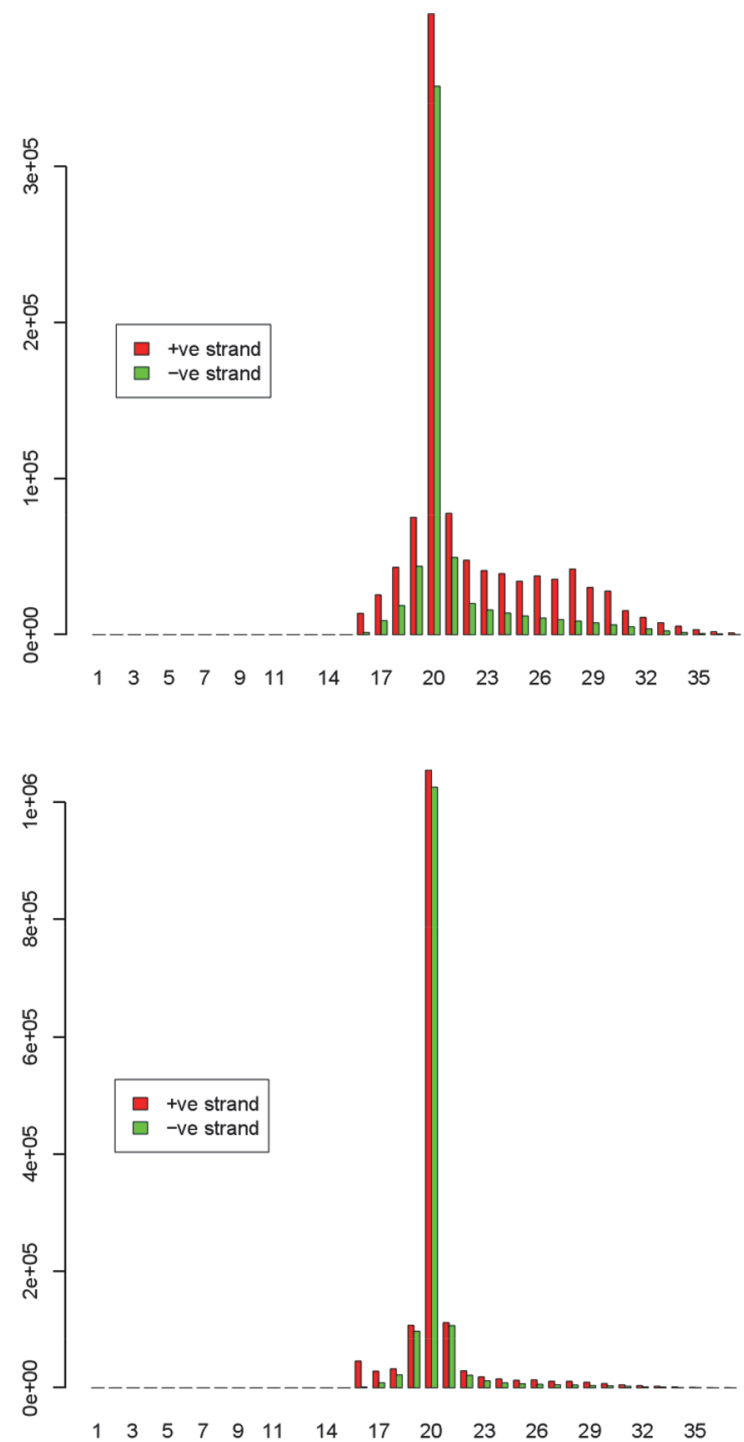

Map length

Fig 2. Size distribution of viral small RNA (vsRNA) reads in persistently and pathogenically BmCPV-infected midgut tissue. Graphs represent read counts that match to the positive or negative strand of BmCPV in persistently and pathogenically infected midguts of $2^{\text {nd }}$ and $4^{\text {th }}$ instar larvae. Numbers of reads (counts) are plotted against the length of the vsRNAs. A clear peak of $20 \mathrm{nt}$ is observed in all samples. Please note also the differences in read counts between persistently (150-200 scale) and pathogenically infected samples ( $3 \times 10^{5}-1 \times 10^{6}$ scale).

doi:10.1371/journal.pone.0121447.g002

i.e. biological process, molecular function and cellular component. Genes belonging to each group were further classified at level 2 for each functional group (Fig. 4).

Gene transcripts found to have at least one"biological process" annotation (426), were further classified in 17 subgroups, with the most important of them belonging to metabolic process (21.1\%), cellular process (18.3\%), single-organism process (15\%), response to stimulus (10.6\%) and multicellular organismal process (10.1\%) (Fig. 4; S3 Fig.). Of note is that the category "immune system process" was poorly represented. Gene transcripts with annotations of molecular function (265) were further classified in 10 categories, among which catalytic activity 


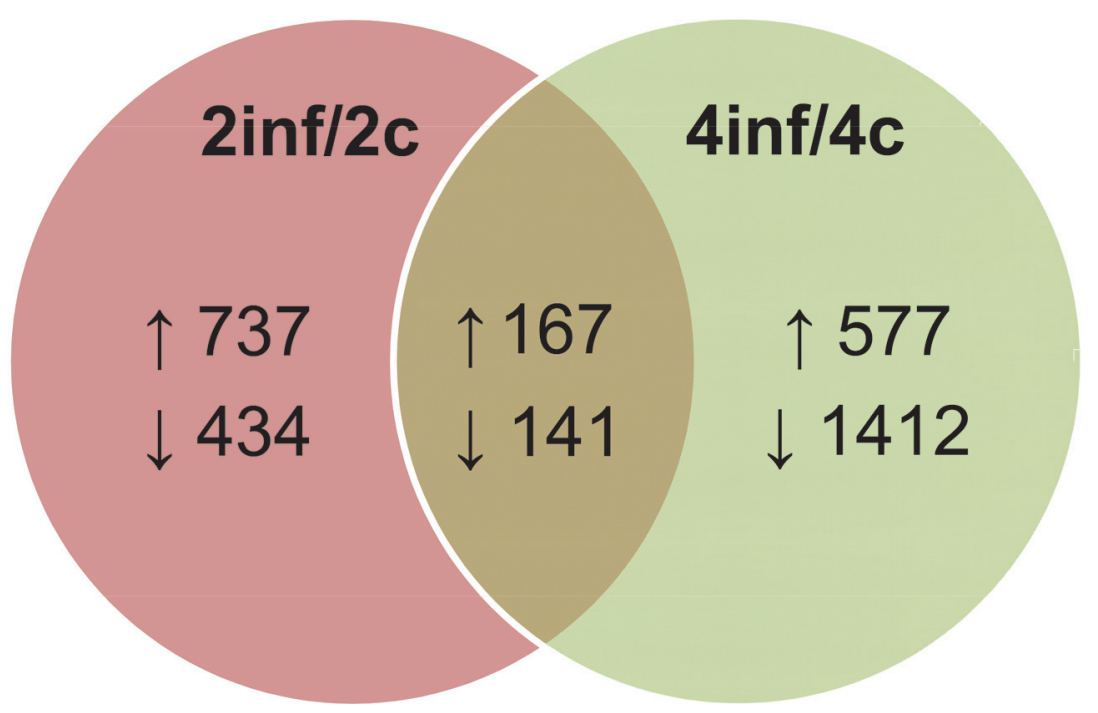

Fig 3. Differentially expressed genes following pathogenic infection in midgut, as determined by deep sequencing analysis. Numbers of up-regulated and down-regulated genes are indicated, after comparison of RPKMs of identified genes between 2inf and $2 \mathrm{c}$ libraries ( $2^{\text {nd }}$ instar), and between 4 inf and $4 \mathrm{c}$ libraries ( $4^{\text {th }}$ instar). The numbers of genes that were up-regulated or down-regulated in both developmental stages are indicated in the section of the two diagrams.

doi:10.1371/journal.pone.0121447.g003

(36.6\%) and binding (36.2\%) represented the most numerous groups. It should be noted that different polymerase (including RNA-directed DNA polymerase), nucleic acid binding and nuclease activities had high rankings (Fig. 4; S3 Fig.). Finally, 117 gene sequences were annotated as cellular components and were further categorized in 8 groups. Membrane (38.5\%), cell (25.6\%), extracellular region (14.5\%) and organelle (12\%) were the four main groups (Fig. 4; S3 Fig.).

\section{Differentially expressed genes and their possible connection to a BmCPV-specific antiviral response}

Several genes possibly implicated in silkworm's response against BmCPV infection were found by deep sequencing to be highly differentially expressed between persistently and pathogenically infected samples (S2 and S3 Datasets). Some of the most interesting genes were further validated by qRT-PCR (Fig. 5; S4 Fig.). These genes fall in several categories, i.e. physical barriers, immune responses, proteolytic enzymes, heat-shock proteins (Table 1), metabolic enzymes, hormonal signaling and uncharacterized, as outlined in detail in Table 2. Together, they constitute a complex response to BmCPV infection in the silkworm larvae.

In the literature, several reports exist with respect to the transcriptome response to $\mathrm{BmCPV}$ infection using larvae without persistent virus infections [15-18]. Table 3 presents a list of all differentially expressed genes obtained from previously published studies and from our study. This list contains only genes of which the differential expression was confirmed by qRT-PCR. In accordance with all four studies, down-regulation of expression of several digestive enzymes was noted; an induction of a small set of immune response genes, of which insulin-binding protein 2 (ibp2) gene was identified as significantly induced in three independent studies ([16, 18]; our study); an induction of the apoptosis pathway or repression of apoptosis inhibitors in four studies ([15-17]; our study) was shown, as well as a role for remodeling of the midgut epithelium during infection (Table 3). For the latter process, it has been speculated that the induction of the cuticle protein-like gene $\mathrm{CPH} 43$, as observed in our study, plays a role. In two studies, 


\section{Biological} process

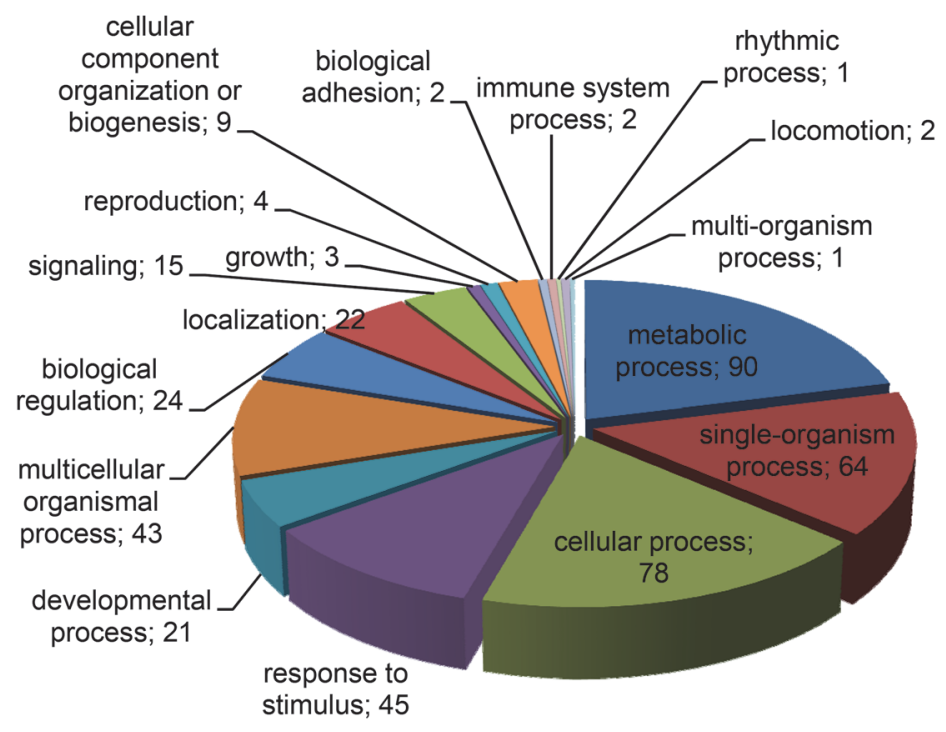

Molecular function

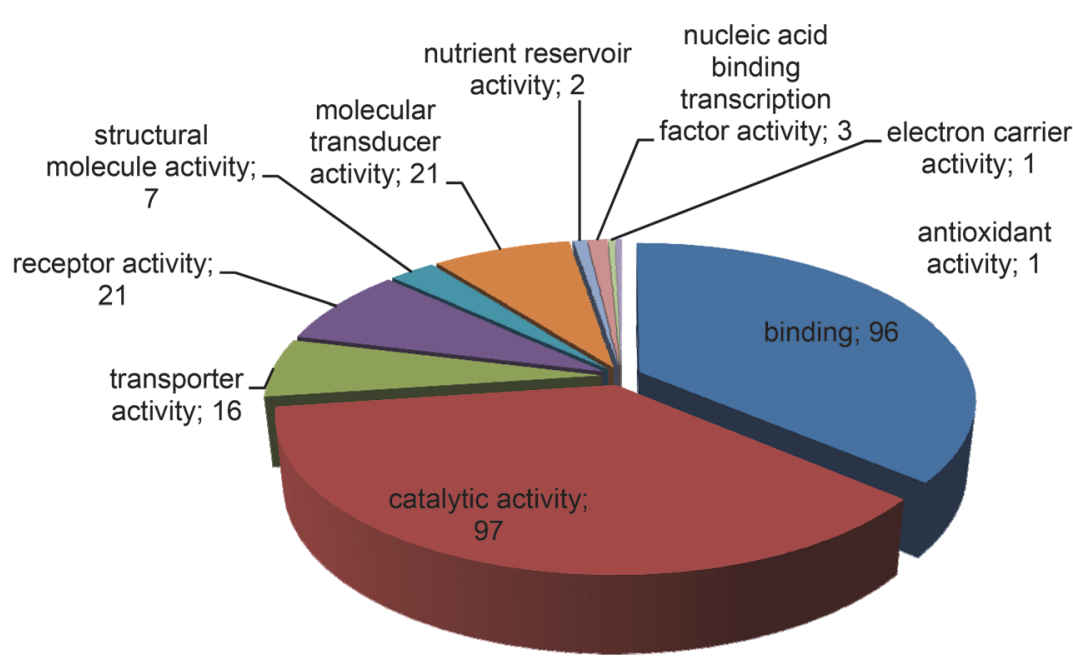

\section{Cellular component}

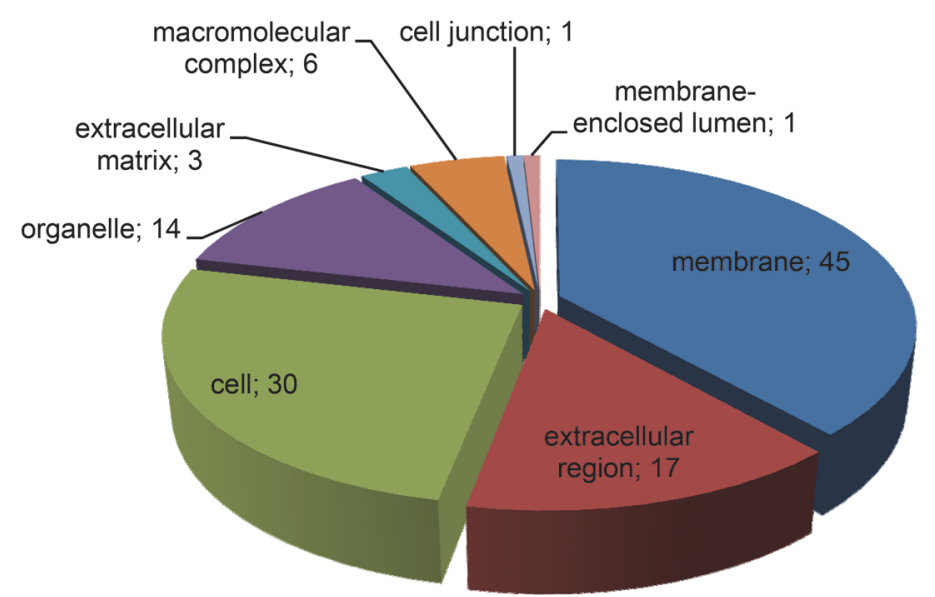

Fig 4. Gene ontology (GO) analysis of differentially expressed genes in pathogenically infected larvae. Genes that were differentially expressed during pathogenic infection at both $2^{\text {nd }}$ and $4^{\text {th }}$ instar developmental stages were analyzed using GO tools and categorized according to biological process, molecular function and cellular component classes. The numbers of genes that could be assigned to the different categories are indicated.

doi:10.1371/journal.pone.0121447.g004 


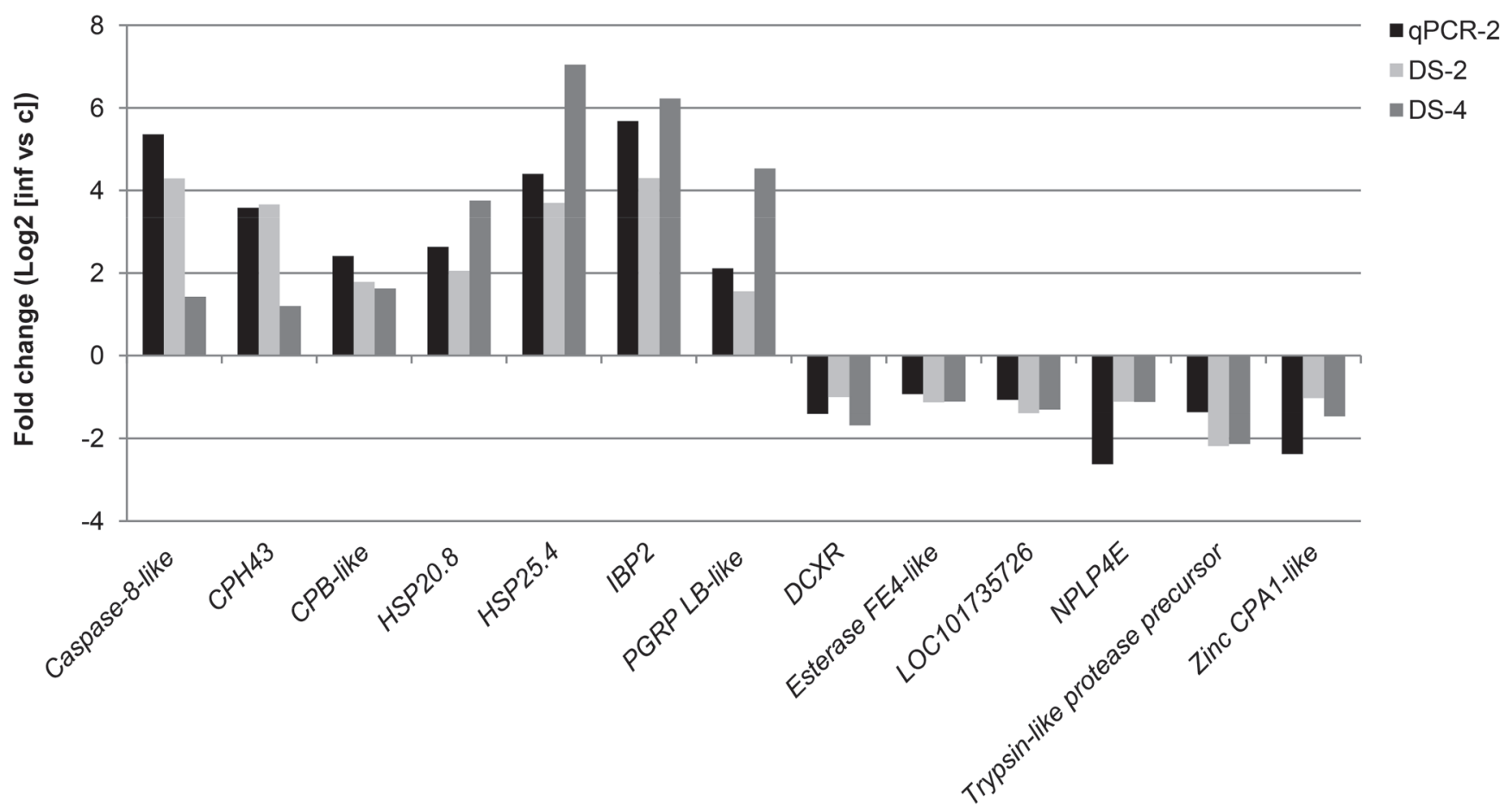

Fig 5. Expression levels of selected genes from pathogenically infected midguts as analyzed by deep sequencing and validated by qRT-PCR. Indicated is the fold change in expression of selected genes between persistent and pathogenic infection as obtained by qRT-PCR on $2^{\text {nd }}$ instar samples (qPCR-2) or by deep sequencing on both $2^{\text {nd }}$ and $4^{\text {th }}$ instar samples (DS-2 and DS-4, respectively). Selected genes belong to the group with highest difference in expression between persistent and pathogenic infection. Please note that fold changes are expressed as log2 values (a 2-fold up- or downregulation corresponds to a log2 value of 1 or -1 , respectively). See Table 2 for further explanation on gene identity and function.

doi:10.1371/journal.pone.0121447.g005

Table 1. Relative RPKMs of genes coding for heat-shock proteins (HSPs).

\begin{tabular}{|c|c|c|c|}
\hline Name & Gene ID & 2inf vs $2 c$ RPKM & 4inf vs $4 c$ RPKM \\
\hline HSP19.9 & BGIBMGA004540 & 8.18 & 20.38 \\
\hline HSP20.8 & BGIBMGA004605 & 4.14 & 13.48 \\
\hline \multirow[t]{2}{*}{ HSP70 } & BGIBMGA006313 & 2.11 & 1.97 \\
\hline & BGIBMGA004614 & 2.37 & 2.19 \\
\hline HSP70, HSC70 & BGIBMGA002381 & 0.96 & 0.98 \\
\hline sHSP 19.1 & BGIBMGA004606 & 0.88 & 2.10 \\
\hline sHSP 19.5 & BGIBMGA013545 & 0.58 & 8.33 \\
\hline sHSP 20.2 & BGIBMGA005784 & 4.52 & na \\
\hline sHSP 20.4 & BGIBMGA004541 & 2.71 & na \\
\hline sHSP 21.4 & BGIBMGA000944 & 1.02 & 1.02 \\
\hline sHSP 22.6 & BGIBMGA004103 & 1.03 & 1.15 \\
\hline sHSP 23.8 & BGIBMGA004515 & 2.78 & 1.88 \\
\hline sHSP 24.2 & BGIBMGA005780 & 3.01 & 0.75 \\
\hline sHSP 26.6 & BGIBMGA005755 & 2.09 & 2.18 \\
\hline sHSP 27.4 & BGIBMGA005823 & 1.97 & 5.26 \\
\hline sHSP 42.3 & BGIBMGA004101 & 0.99 & 0.44 \\
\hline
\end{tabular}

Ratios of RPKM values from pathogenically versus persistently infected midgut tissue of $2^{\text {nd }}$ and $4^{\text {th }}$ instar larvae obtained by deep sequencing analysis (2c, 2inf, 4c and 4inf samples) are presented for heat-shock protein genes. Genes presenting higher than 1.5-fold up- or down-regulation are marked with bold letters. Abbreviation: na: not applicable.

doi:10.1371/journal.pone.0121447.t001 
Table 2. Selected highly differentially expressed genes following pathogenic infection of midgut tissue.

\begin{tabular}{ll}
\hline Category/ Name & Known/ Possible function \\
\hline $\begin{array}{l}\text { Physical barrier } \\
\text { CPH43 }\end{array}$ & putative cuticle gene; involved in larval molting [31] \\
Immune responses & $\begin{array}{l}\text { highly homologous to IGFBP7 in vertebrates (tumor-suppressive function leading to apoptosis); involved in immune } \\
\text { and endocrine responses [32-37] } \\
\text { IBP2 }\end{array}$ \\
& $\begin{array}{l}\text { insulin signaling pathway is reported to be involved in the defense against pathogens in C. elegans [38] } \\
\text { Drosophila cells and insect gut epithelium [39] }\end{array}$ \\
& $\begin{array}{l}\text { behaves as an amidase; hydrolyzes Gram- bacteria peptidoglycan and is activated by them; indirectly acts as negative } \\
\text { regulator of the IMD pathway, thus balancing homeostasis and immune response activation [40, 41] }\end{array}$
\end{tabular}

\section{Proteolytic enzymes}

Caspase-8-like

$C P B$

Trypsin-like protease precursor death receptor-associated initiator caspase-8 is expected to be activated upon reovirus infection in the case of reovirus-induced apoptosis [42-45]

up-regulated in the midgut of Anopheles gambiae mosquitoes infected with Plasmodium falciparum parasite, significantly reduced growth and development of rodent parasite $P$. berghei in mosquitos fed on infected mice immunized against CPB [46]

alkaline protease; active in the silkworm midgut alkaline environment; participates in the hydrolysis of incoming food and probably also of viral polyhedra, thus mediating release of occluded viruses and infection of midgut columnar epithelial cells [47]

trypsin-like protease is down-regulated in BmDNV-Z and BmNPV-infected silkworm strains susceptible to the respective viruses, up-regulated in BmNPV-infected silkworm strain [47, 48]

facilitates DENV-2 virus infection in Aedes aegypti [49]

Zinc carboxypeptidase A1-like (CPA1)

Heat-shock proteins

HSPs; HSCs

Metallocarboxypeptidase $\mathrm{ACl}$, a zinc carboxypeptidase $\mathrm{A} 1$ (CPA1) inhibitor, is expressed by Ascaris (human intestinal parasite) to enhance its survival during infection [50]

molecular chaperones in various cellular processes; danger signals thus activating host immune response [51,52] HSPs and HSCs are necessary for efficient BmNPV proliferation in Bombyx cells as well as for PCV2 virus expansion in porcine cells [53-55]

sHSPs are induced in BmCPV-infected larval midguts [18]

Hsp25 has antiviral role in reovirus-infected murine cells [56]; HSC70 is up-regulated in BmCPV-infected silkworms (72hpi) [18]; Hsc70t and HSP105 are induced by reovirus infection in murine cells [57]

Metabolic enzymes

$D C X R$

converts L-xylulose in xylitol (carbohydrate metabolism); reduces the highly reactive a-dicarbonyl compounds (DCs) with endogenous/ xenobiotic origin (detoxifying enzyme) [58]

DHS-21 (DCXR ortholog) is essential for normal life-span and reproduction of C. elegans [59]

Esterase FE4-like esterases hydrolyze and inactivate insecticides (insecticide resistance), but also metabolize pathogen-secreted toxic compounds (host response) [60]; as counter-mechanism, pathogens may synthesize inhibitors against such esterase function to cause down-regulation of esterase genes

Hormonal signaling

NPLP4E

neuropeptides: signaling molecules playing key roles in insects due to their involvement in developmental, reproductive, metabolic and behavioral processes; expressed in several tissues (brain, epidermis, ovary, prothoracic gland); possibly involved in molting regulation [61]

NPLP4E maybe carries out additional functions in the midgut (here was first detected to be expressed) [31, 62]

Uncharacterized

LOC101735726

possible role in the physiological process of DNA replication and maintenance (S5 Fig.) which may be hindered due to BmCPV presence in the midgut

The list represents genes with high differential expression levels during pathogenic infection detected by deep sequencing analysis that were also validated by qRT-PCR. The selected genes are categorized according to their function. Relevant studies representing similar responses to infection are also listed.

doi:10.1371/journal.pone.0121447.t002 
Table 3. Classification of genes that are induced or repressed following pathogenic BmCPV infection: comparison among different relevant studies.

\begin{tabular}{|c|c|c|c|c|c|c|}
\hline Genes & SH (p50) ${ }^{[17]}$ & MA (p50) ${ }^{[18]}$ & DS (4008) ${ }^{[15]}$ & DS $(4008)^{[16]}$ & DS $(p 50)^{[16]}$ & D (DaiSzo) our study \\
\hline \multicolumn{7}{|c|}{ digestive enzymes (proteases, lipases, nucleases) } \\
\hline Acidic lipase & & & $\leftarrow$ & & & \\
\hline Alkaline nuclease & $\rightarrow$ & & & & & \\
\hline Chymotrypsin-like & & & $\leftarrow$ & & $\leftarrow$ & \\
\hline Hemocyte protease-2 & & $\rightarrow$ & & & & \\
\hline Insect intestinal lipase- 6 & & & & & $\leftarrow$ & \\
\hline Lipase-1 & & $\rightarrow$ & $\leftarrow$ & & $\leftarrow$ & \\
\hline Pancreatic lipase-like & & & & & $\rightarrow$ & \\
\hline Serine protease & $\leftarrow$ & & & & & \\
\hline Trypsin-like & $\leftarrow$ & & & & & $\leftarrow$ \\
\hline Zinc carboxypeptidase A1 & & & & & & $\leftarrow$ \\
\hline \multicolumn{7}{|l|}{ detoxification/metabolism } \\
\hline Antennal esterase CXE14 & & & $\leftarrow$ & & & \\
\hline Aquaporin & & & & $\rightarrow$ & & \\
\hline Cytochrome $P 450$ & & $\rightarrow$ & & & & \\
\hline Dicarbonyl/L-xylulose reductase & & & & & & $\leftarrow$ \\
\hline Esterase FE4 & & & & & & $\leftarrow$ \\
\hline Farnesyl diphosphate synthase & & & & $\rightarrow$ & & \\
\hline Fatty acid binding protein & & & $\leftarrow$ & & & \\
\hline Similar to carboxylesterase & & $\leftarrow$ & & & & \\
\hline Sugar transporter & & & $\leftarrow$ & & & \\
\hline Putative galactose UDP 4-epimerase & & & $\rightarrow$ & & & \\
\hline \multicolumn{7}{|l|}{ stress response } \\
\hline elF-4E-1 & & & & & & $\rightarrow$ \\
\hline HSP 20.8 & & & & & & $\rightarrow$ \\
\hline HSP 23.7 & & $\rightarrow$ & & & & \\
\hline HSP25.4 & & & & & & $\rightarrow$ \\
\hline \multicolumn{7}{|l|}{ signaling } \\
\hline Calreticulin & & & $\rightarrow$ & & & \\
\hline Coiled-coil \& C2 domain-containing $2 A$ & & & & & $\rightarrow$ & \\
\hline Ecdysteroid-22 kinase & & & & $\rightarrow$ & & \\
\hline Famesoic acid O-methyltransferase & & & $\rightarrow$ & & & \\
\hline FK506-binding protein precursor & & & $\rightarrow$ & & & \\
\hline GTP:AMP phosphotransferase & & $\leftarrow$ & & & & \\
\hline GTP-binding protein RAB2 & & & & $\rightarrow$ & & \\
\hline Inorganic phosphate transporter 1 & & & $\leftarrow$ & & & \\
\hline Juvenile hormone diol kinase & & $\rightarrow$ & & & $\rightarrow$ & \\
\hline Neuropeptide-like 4E (NPLP4E) & & & & & & $\leftarrow$ \\
\hline Palmityl transferase (P260) & & & & $\leftarrow$ & $\leftarrow$ & \\
\hline Protein kinase $C$ inhibitor & & & $\rightarrow$ & & & \\
\hline Troponin-C & & & & & $\rightarrow$ & \\
\hline \multicolumn{7}{|l|}{ immune response } \\
\hline Antitrypsin precursor & & $\leftarrow$ & & & & \\
\hline Insulin-binding protein 2 & & $\rightarrow$ & & & $\rightarrow$ & $\rightarrow$ \\
\hline Peptidoglycan recognition protein LB-like & & & & & & $\rightarrow$ \\
\hline Serpin-5 & & $\rightarrow$ & & & & \\
\hline
\end{tabular}

(Continued) 
Table 3. (Continued)

\begin{tabular}{|c|c|c|c|c|c|c|}
\hline Genes & SH $(p 50)^{[17]}$ & MA (p50) $)^{[18]}$ & DS (4008) ${ }^{[15]}$ & DS (4008) ${ }^{[16]}$ & DS (p50) ${ }^{[16]}$ & D (DaiSzo) our study \\
\hline Serpin-28 & & & & $\rightarrow$ & & \\
\hline Thioredoxin-like & & & & $\rightarrow$ & & \\
\hline Tumor necrosis factor 13 (TNFSF13) & & & & $\rightarrow$ & & \\
\hline \multicolumn{7}{|l|}{ RNAi } \\
\hline Argonaute-2 & & & & & & $\rightarrow$ \\
\hline Dicer-2 & & & & & & $\rightarrow$ \\
\hline \multicolumn{7}{|l|}{ apoptosis } \\
\hline Carboxypeptidase $B$ & & & & & & $\rightarrow$ \\
\hline Caspase-8 & & & & & & $\rightarrow$ \\
\hline Inhibitor-of-apoptosis & $\leftarrow$ & & & & & \\
\hline Programmed cell death protein 5 & & & $\rightarrow$ & & & \\
\hline Putative apoptosis inhibitor 5 & & & & $\leftarrow$ & & \\
\hline $30 K$ protein 26 & & & & & $\leftarrow$ & \\
\hline \multicolumn{7}{|l|}{ ubiquitin-proteasome } \\
\hline Goliath E3 ubiquitin ligase & & & & $\rightarrow$ & & \\
\hline Ubiquitin-conjugating enzyme E2 J1-like & & & & $\rightarrow$ & & \\
\hline \multicolumn{7}{|l|}{ midgut remodeling—cuticle } \\
\hline $\mathrm{CPH} 43$ & & & & & & $\rightarrow$ \\
\hline Urbain precursor & & & & $\rightarrow$ & & \\
\hline 37 kDa protease precursor & & & & $\rightarrow$ & & \\
\hline \multicolumn{7}{|l|}{ iron metabolism } \\
\hline Ferritin & $\rightarrow$ & & & & & \\
\hline Transferrin & & & & $\rightarrow$ & $\rightarrow$ & \\
\hline \multicolumn{7}{|l|}{ ribosomal proteins } \\
\hline L11 & $\rightarrow$ & & & & & \\
\hline PO & & $\rightarrow$ & & & & \\
\hline \multicolumn{7}{|l|}{ unknown } \\
\hline LOC101735726 & & & & & & $\leftarrow$ \\
\hline Protein KGM_04122 & & & & & $\leftarrow$ & \\
\hline Protein KGM16290 & & & & & $\leftarrow$ & \\
\hline Similar to CG10527 & & & & & $\rightarrow$ & \\
\hline Similar to CG8927 & & & & $\rightarrow$ & & \\
\hline Unknown secreted protein & & & $\rightarrow$ & & & \\
\hline $30 \mathrm{kDa}$ protein & & & & & $\rightarrow$ & \\
\hline
\end{tabular}

Only genes confirmed by qRT-PCR (more than 2-fold difference in response) are shown. Induced and repressed genes are marked with up and down arrows respectively. Empty cells indicate that the particular gene was not tested by qRT-PCR for differential expression in the particular study.

Abbreviations: SH: subtractive hybridization, MA: microarray, DS: deep sequencing. P50, 4008 and Daizo refer to silkworm strains.

doi:10.1371/journal.pone.0121447.t003

induction of the stress response, represented by small heat-shock protein genes (Table 1), was observed ([18]; our study). The two studies by Gao et al. [15, 16] also emphasized the possible role of the calcium-signaling pathway to induce apoptosis in infected cells, but the calcium signaling pathway genes were not among the most differentially genes that were analyzed by qRT-PCR in the other studies.

The differences in transcriptional response among the four studies can be explained by the use of different silkworm strains, stage of infection and time of collection of infected samples. Gao et al. [16] compared the transcriptional response to BmCPV between a relatively resistant 
(p50) and a susceptible (4008) silkworm strain and found important differences in the response to virus infection. Of interest, it was observed that ibp2 gene was induced at high levels only in the resistant strain. Therefore it was considered as a gene involved in resistance against $\mathrm{BmCPV}$. The observation of induction of $i b p 2$ during pathogenic infection in our study suggests the existence of an active antiviral resistance mechanism during persistent infection with BmCPV.

\section{Transcriptional response of RNAi-related genes to infection with BmCPV in $B$. mori}

As outlined in the introduction, a second goal in our study was to assess the RNAi response during a persistent and pathogenic infection with BmCPV since this response did not receive much attention in previous studies. Therefore, the transcriptional response of RNAi-related genes in the host tissues was examined, while the production of vsRNAs was also investigated.

It is well known that in Drosophila and mosquitoes, the siRNA pathway (and piRNA pathway in mosquitoes) can play an active role in the defense against exogenous invading singlestranded and double-stranded RNAs [63]. Due to the fact that the BmCPV genome consists of 10 segments of dsRNA, it was speculated that it could act as a target for the RNAi mechanism during the establishment of pathogenic BmCPV infection in Bombyx larvae. Therefore, it would be interesting to investigate whether pathogenic infection could up-regulate the expression of RNAi-related genes as an antiviral response mechanism during pathogenic infection.

Following application of the BLASTP algorithm in the NCBI database on the B. mori genome, as well as use of the BLAST tool in the www.silkdb.org database, homologs (annotated or not) of several RNAi-related genes originally implicated in the RNAi process in other organisms were identified in the silkworm's genome (for a discussion of different categories of RNAi-related genes, see [64]). Deep sequencing data were then analyzed to pinpoint alterations of the expression of RNAi-related genes following a pathogenic infection with BmCPV. The expression of several core RNAi genes and additional RNAi-related factors (Table 4) was further confirmed by qRT-PCR in $2^{\text {nd }}$ instar midgut cDNA samples (Fig. 6; S6 Fig.).

Three genes of the Argonaute family (i.e. Ago1, Ago2 and Ago 3 that represent the miRNA, siRNA and piRNA pathway, respectively), as well as Dcr2 from the siRNA pathway, are considered as core RNAi genes in B. mori, since inhibition of their expression by use of the "RNAi-ofthe RNAi" method caused a significant impediment of the silencing potency in the silkwormderived Bm5 cells [65]. In addition, several other core RNAi genes, such as Aubergine (SIWI; piRNA pathway) and Loquacious (dsRNA binding protein; miRNA pathway), were also analyzed in the deep sequencing database and by qRT-PCR (Table 4; Fig. 6; S6 Fig.).

Regarding the siRNA pathway, the genes Ago2 and Dcr2, which are well known to be responsible for the defense against exogenous dsRNAs in Drosophila, showed a $\sim 2$-fold up-regulation in expression during the pathogenic infection (Table 4; Fig. 6; S6 Fig.). The piRNA pathway gene Aubergine was found to be 1.5 -fold up-regulated in the $4^{\text {th }}$ instar animals after feeding with polyhedra; however, this result was not confirmed for the $2^{\text {nd }}$ instar stage. Also for Loquacious (miRNA pathway), no important differential expression between the two types of infection was observed (Table 4; Fig. 6; S6 Fig.).

Apart from the core RNAi components, additional RNAi-related genes were selected [64]. Tudor staphylococcus / micrococcal nuclease (Tudor-SN) and eukaryotic initiation factor-4E1 (eIF-4E1) were recently shown to constitute core factors for the formation of stress granules (SGs) in silkworm BmN4 cells, while they possibly also interact with Ago1 and Ago2 proteins of the miRNA and the siRNA pathway, respectively [66]. Tudor-SN expression was not notably altered after a pathogenic infection with BmCPV (Table 5; Fig. 6; S6 Fig.). Interestingly, 
Table 4. Relative RPKMs of genes coding for core RNAi factors.

\begin{tabular}{lll}
\hline Core RNAi factors & 2inf vs 2c RPKM & 4inf vs 4c RPKM \\
\hline miRNA pathway & & \\
\hline Pasha (part 1) & 0.86 & 1.19 \\
\hline Pasha (part 2) & 0.81 & 1.18 \\
\hline Dicer-1-like (part 1) & 0.97 & 0.96 \\
\hline Dicer-1-like (part 2) & 1.03 & 0.91 \\
\hline Loquacious & 0.94 & 1.28 \\
\hline Argonaute 1 & 1.12 & 1.20 \\
\hline siRNA pathway & & \\
\hline Dicer 2 (part 1) & 2.20 & 2.08 \\
\hline Dicer 2 (part 2) & 2.01 & 1.97 \\
\hline R2D2 & 1.20 & 1.06 \\
\hline Argonaute 2 & 1.98 & 1.48 \\
\hline piRNA pathway & & \\
\hline Argonaute 3 & 1.10 & 0.89 \\
\hline Piwi/ Aubergine & 1.20 & 1.54 \\
\hline
\end{tabular}

Ratios of RPKM values from pathogenically versus persistently infected midgut tissue of $2^{\text {nd }}$ and $4^{\text {th }}$ instar larvae obtained by deep sequencing analysis (2c, 2inf, 4c and 4inf samples) are presented for selected genes belonging to the miRNA, siRNA and piRNA pathways. Genes presenting higher than 1.5-fold up- or down-regulation are marked with bold letters.

doi:10.1371/journal.pone.0121447.t004

however, the expression level of eIF-4E1 was up-regulated during the pathogenic infection (from 2- to 8-fold, depending on the technique used and the sample; Table 5; Fig. 6; S6 Fig.). The increase of the relative mRNA level could be due to the general stress state caused by the infection, or due to a special role of eIF-4E1 in the midgut response.

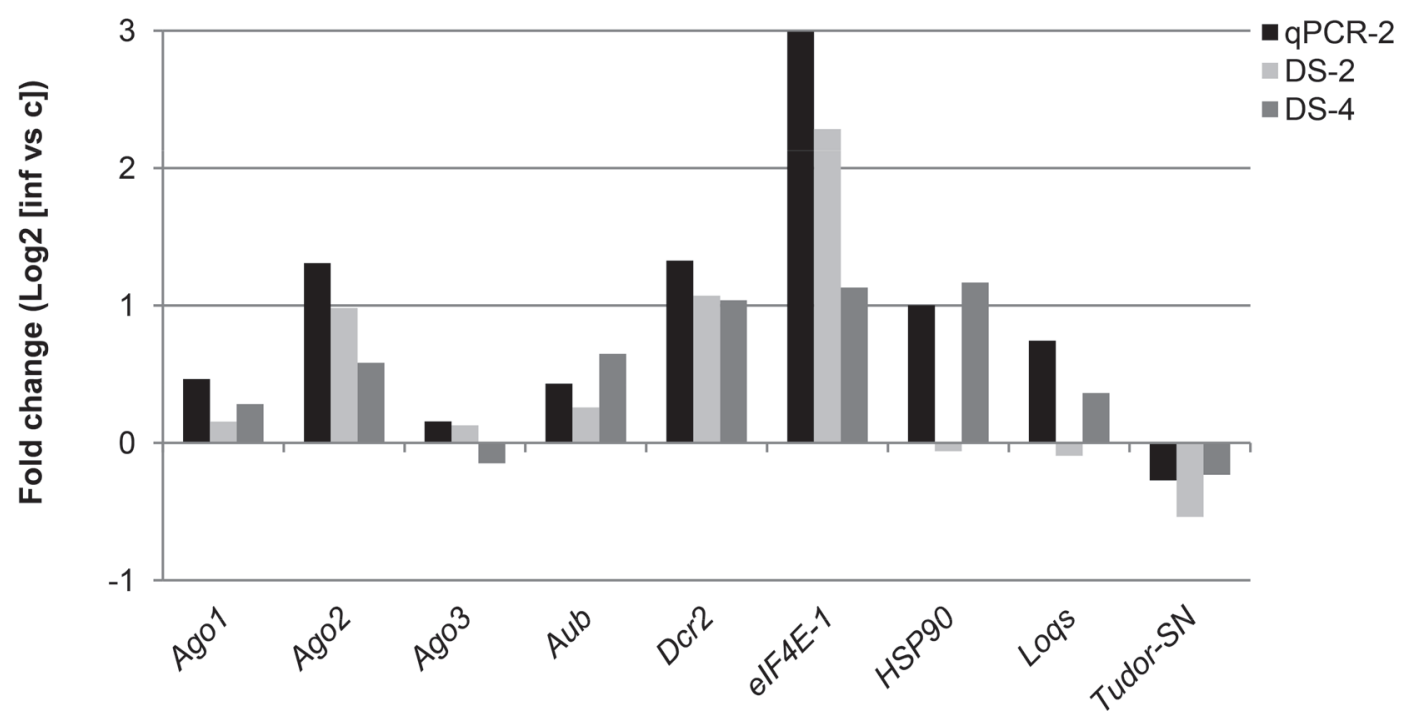

Fig 6. Expression levels of RNAi-related genes from pathogenically infected midguts as analyzed by deep sequencing and validated by qRT-PCR. Indicated is the fold change in expression of selected genes between persistent and pathogenic infection as obtained by qRT-PCR on $2^{\text {nd }}$ instar samples (qPCR-2) or by deep sequencing on both $2^{\text {nd }}$ and $4^{\text {th }}$ instar samples (DS-2 and DS-4, respectively). Please note that fold changes are expressed as log2 values (a 2-fold up- or down-regulation corresponds to a log2 value of 1 or -1 , respectively). See Table 5 and [64] for further explanation on gene identity and function.

doi:10.1371/journal.pone.0121447.g006 
Table 5. Relative RPKMs of RNAi-related genes.

\begin{tabular}{|c|c|c|c|c|c|}
\hline RNAi factors & Closest homolog in B. mori & $\begin{array}{l}\text { GenBank Accession } \\
\text { Number }\end{array}$ & Gene ID & $\begin{array}{l}\text { 2inf vs } \\
\text { 2c } \\
\text { RPKM }\end{array}$ & $\begin{array}{l}\text { 4inf vs } \\
4 c \\
\text { RPKM }\end{array}$ \\
\hline \multicolumn{6}{|l|}{ Intracellular auxiliary factors } \\
\hline $\begin{array}{l}\text { Arginine methyltransferase PRMT5 } \\
\text { (dPRMT5, also called capsuleen or } \\
\text { dart5) }\end{array}$ & $\begin{array}{l}\text { protein arginine N-methyltransferase } \\
5 \text {-like isoform X1 or X2 (predicted) }\end{array}$ & $\begin{array}{l}\text { XP_004928553.1/ } \\
\text { XP_004928554.1 }\end{array}$ & BGIBMGA007842 & 1.11 & 1.46 \\
\hline Armitage & $\begin{array}{l}\text { probable RNA helicase armi-like } \\
\text { (predicted)* }\end{array}$ & XP_004933936.1 & BGIBMGA005056 & 1.13 & 0.95 \\
\hline $\begin{array}{l}\text { ATP-dependent RNA helicase } \\
\text { Belle }\end{array}$ & $\begin{array}{l}\text { ATP-dependent RNA helicase DDX3X } \\
\text { isoform X1 or X2 (predicted) }\end{array}$ & $\begin{array}{l}\text { XP_004924684.1/ } \\
\text { XP_004924685.1 }\end{array}$ & BGIBMGA007594 & 1.05 & 1.26 \\
\hline Clp1 homolog (kinase) & protein CLP1 homolog (predicted) & XP_004923397.1 & BGIBMGA004784 & 1.03 & 1.20 \\
\hline \multirow[t]{4}{*}{$\begin{array}{l}\text { Drosophila homolog of p68 RNA } \\
\text { helicase }\end{array}$} & DEAD box polypeptide 5 isoform 1 or 2 & $\begin{array}{l}\text { NP_001037582.1/ } \\
\text { NP_001166829.1 }\end{array}$ & BGIBMGA011746 & 1.31 & 1.42 \\
\hline & DEAD box polypeptide 5 isoform 1 or 2 & $\begin{array}{l}\text { NP_001037582.1/ } \\
\text { NP_001166829.1 }\end{array}$ & BGIBMGA011754 & 1.12 & 1.15 \\
\hline & DEAD box polypeptide 5 isoform 1 or 2 & $\begin{array}{l}\text { NP_001037582.1/ } \\
\text { NP_001166829.1 }\end{array}$ & BGIBMGA011965 & 1.05 & 1.22 \\
\hline & DEAD box polypeptide 5 isoform 1 or 2 & $\begin{array}{l}\text { NP_001037582.1/ } \\
\text { NP_001166829.1 }\end{array}$ & BGIBMGA012013 & 0.88 & 0.87 \\
\hline Elp-1 & elongator complex protein 1 & NP_001182006.1 & BGIBMGA001538 & 0.94 & 0.97 \\
\hline Eukaryotic initiation factor $4 \mathrm{E}-1$ & eukaryotic initiation factor $4 \mathrm{E}-1$ & NP_001091832.1 & BGIBMGA012675 & 4.89 & 2.16 \\
\hline Gawky CG31992-PA (similar) & $\begin{array}{l}\text { trinucleotide repeat-containing gene } 6 \mathrm{~B} \\
\text { protein-like (predicted)/ protein Gawky- } \\
\text { like (predicted) }\end{array}$ & $\begin{array}{l}\text { XP_004922030.1/ } \\
\text { XP_004922029.1 }\end{array}$ & BGIBMGA005589 & 1.12 & 0.90 \\
\hline Gemin 3 homolog & $\begin{array}{l}\text { probable ATP-dependent RNA helicase } \\
\text { DDX20-like (predicted) }\end{array}$ & XP_004931522.1 & BGIBMGA011804 & 0.77 & 1.41 \\
\hline HEN1 & $\begin{array}{l}\text { small RNA 2'-O-methyltransferase-like } \\
\text { (predicted) }\end{array}$ & XP_004928786.1 & BGIBMGA007679 & 1.21 & 0.79 \\
\hline Homeless (spindle-E) & $\begin{array}{l}\text { probable ATP-dependent RNA helicase } \\
\text { spindle-E-like (predicted) }\end{array}$ & XP_004924494.1 & BGIBMGA004949 & 0.92 & 1.43 \\
\hline Maelstrom & protein maelstrom homolog (predicted) & XP_004928380.1 & BGIBMGA008424 & 1.08 & 1.32 \\
\hline$x$ Putative translin-associated factor & $\begin{array}{l}\text { translin-associated protein X-like } \\
\text { (predicted) }\end{array}$ & XP_004927402.1 & BGIBMGA004644 & nd & nd \\
\hline Staufen & $\begin{array}{l}\text { maternal effect protein staufen-like } \\
\text { (predicted) }\end{array}$ & XP_004932448.1 & BGIBMGA002695 & 1.12 & 0.88 \\
\hline Translin & translin & ABD36365.1 & BGIBMGA009726 & 1.07 & 1.38 \\
\hline Tudor-SN & $\begin{array}{l}\text { tudor staphylococcus/micrococcal } \\
\text { nuclease }\end{array}$ & NP_001182009.1 & BGIBMGA013328 & 0.69 & 0.85 \\
\hline Vasa intronic gene (VIG) & $\begin{array}{l}\text { plasminogen activator inhibitor } 1 \text { RNA- } \\
\text { binding protein-like }\end{array}$ & NP_001266293.1 & BGIBMGA006704 & 1.07 & 0.86 \\
\hline \multicolumn{6}{|l|}{ DsRNA uptake } \\
\hline $\begin{array}{l}\text { CG4966 (orthologous to the } \\
\text { Hermansky- Pudlak Syndrome 4, } \\
\text { HPS4) }\end{array}$ & $\begin{array}{l}\text { uncharacterized protein LOC101743016 } \\
\text { (predicted)* }\end{array}$ & XP_004923697.1 & BGIBMGA009850 & 1.16 & 0.51 \\
\hline Eater & $\begin{array}{l}\text { neurogenic locus notch homolog protein } \\
1 \text {-like (predicted) * }\end{array}$ & XP_004931260.1 & BGIBMGA002383 & 1.33 & 0.79 \\
\hline FBX011 ortholog & $\begin{array}{l}\text { F-box only protein } 11 \text {-like isoform } \mathrm{X} 1 \text { or } \\
\mathrm{X} 2 \text { (predicted) }\end{array}$ & $\begin{array}{l}\text { XP_004924574.1/ } \\
\text { XP_004924575.1 }\end{array}$ & BGIBMGA005003 & 1.09 & 1.12 \\
\hline $\begin{array}{l}\text { Scavenger receptor SR-C-like } \\
\text { protein }\end{array}$ & scavenger receptor type $\mathrm{C}$ precursor & NP_001128387.1 & BGIBMGA004577 & 2.15 & 0.33 \\
\hline
\end{tabular}


Table 5. (Continued)

\begin{tabular}{|c|c|c|c|c|c|}
\hline RNAi factors & Closest homolog in B. mori & $\begin{array}{l}\text { GenBank Accession } \\
\text { Number }\end{array}$ & Gene ID & $\begin{array}{l}\text { 2inf vs } \\
\text { 2c } \\
\text { RPKM }\end{array}$ & $\begin{array}{l}4 \text { inf vs } \\
4 c \\
\text { RPKM }\end{array}$ \\
\hline \multirow[t]{4}{*}{ Sid-1-like protein 1} & $\begin{array}{l}\text { sid-1-related gene } 1 \text { precursor/ low } \\
\text { quality protein: SID1 transmembrane } \\
\text { family member } 1 \text { (predicted) }\end{array}$ & $\begin{array}{l}\text { NP_001106735.1/ } \\
\text { XP_004930735.1 }\end{array}$ & BGIBMGA011251 & 1.14 & 0.95 \\
\hline & sid-1-related gene 1 precursor & NP_001106735.1 & BGIBMGA011160 & 0.92 & 0.87 \\
\hline & sid-1-related gene 1 precursor & NP_001106735.1 & BGIBMGA011161 & 0.71 & 1.15 \\
\hline & $\begin{array}{l}\text { low quality protein: SID1 transmembrane } \\
\text { family member } 1 \text { (predicted) }\end{array}$ & XP_004930735.1 & BGIBMGA011250 & 0.99 & 1.08 \\
\hline Sid-1-like protein 2 & sid-1-like protein 2 & BAF95807.1 & BGIBMGA011251 & 1.14 & 0.95 \\
\hline Sid-1-like protein 3 & sid-1-related gene 3 precursor & NP_001106736.1 & BGIBMGA005847 & 0.93 & 0.84 \\
\hline \multicolumn{6}{|l|}{ Antiviral RNAi } \\
\hline Ars2 & $\begin{array}{l}\text { low quality protein: serrate RNA effector } \\
\text { molecule homolog (predicted) }\end{array}$ & XP_004930189.1 & BGIBMGA003480 & 0.94 & 1.08 \\
\hline CG4572 & $\begin{array}{l}\text { venom serine carboxypeptidase-like } \\
\text { (predicted) }\end{array}$ & XP_004929002.1 & BGIBMGA013085 & 1.01 & 1.85 \\
\hline Egghead & glycosyltransferase precursor & NP_001243979.1 & BGIBMGA001169 & 1.34 & 1.52 \\
\hline NinaC & myosin-IIla-like (predicted) & XP_004930229.1 & BGIBMGA003454 & 1.46 & 0.67 \\
\hline \multicolumn{6}{|l|}{ Nucleases } \\
\hline dsRNase & alkaline nuclease precursor & NP_001091744.1 & BGIBMGA001173 & 0.55 & 0.85 \\
\hline Exosome & PM-Scl autoantigen-like protein & NP_001108472.1 & BGIBMGA000626 & 1.34 & 0.77 \\
\hline Nibbler & $\begin{array}{l}\text { probable exonuclease mut-7 homolog } \\
\text { (predicted) }\end{array}$ & XP_004931095.1 & BGIBMGA002947 & 0.84 & 0.94 \\
\hline $\begin{array}{l}\text { Poly(A) polymerase (Pla1 } \\
\text { homolog Schizosaccharomyces) }\end{array}$ & $\begin{array}{l}\text { poly }(\mathrm{A}) \text { polymerase gamma-like isoform } \\
\mathrm{X} 1 \text { (predicted) }\end{array}$ & XP_004923145.1 & BGIBMGA000084 & 1.29 & 1.02 \\
\hline $\begin{array}{l}\text { Sdn1-like (small RNA-degrading } \\
\text { nuclease 1) }\end{array}$ & $\begin{array}{l}\text { putative RNA exonuclease NEF-sp-like } \\
\text { (predicted) }\end{array}$ & XP_004931480.1 & BGIBMGA011782 & 0.84 & 1.31 \\
\hline \multicolumn{6}{|l|}{ Other factors } \\
\hline Exportin-5 & exportin-5-like (predicted) & XP_004928015.1 & BGIBMGA001123 & 0.92 & 1.02 \\
\hline HSP90 & HSP90, partial & AEB39782.1 & BGIBMGA004612 & 0.96 & 2.24 \\
\hline
\end{tabular}

Ratios of RPKM values from pathogenically versus persistently infected midgut tissue of $2^{\text {nd }}$ and $4^{\text {th }}$ instar larvae obtained by deep sequencing analysis (2c, 2inf, 4c and 4inf samples) are presented for selected genes with a role in the RNAi mechanism. Listed are intracellular auxiliary factors, dsRNA uptake genes, antiviral RNAi genes, nucleases and unclassified factors [64]. Genes presenting higher than 1.5-fold up- or down-regulation are marked with bold letters. Abbreviation: nd: not detected.

doi:10.1371/journal.pone.0121447.t005

Heat shock protein 90 (HSP90) is an important factor that lately has emerged as a key piRNA pathway regulator. HSP90 was shown to take part in the piRNA pathway in BmN4 cells, more specifically in the recruitment of precursor piRNA molecules by the PIWI proteins $[67,68]$. Although deep sequencing analysis showed a $>2$-fold up-regulation of HSP90 in the $4^{\text {th }}$ instar library of pathogenically infected midgut tissue, this was not confirmed in the respective $2^{\text {nd }}$ instar sample (Table 5; Fig. 6; S6 Fig.). These data indicate that the role of HSP90 is relatively minor in this type of infection, in sharp contrast to other HSPs as shown in Tables 1-3.

Regarding genes involved in dsRNA uptake, CG4572 and HPS4 only showed clear differential expression between pathogenic and persistent infection in the $4^{\text {th }}$ instar animals. Also for the moderately expressed scavenger receptor- $C(S R-C)$, no clear differential expression was observed (Table 5). 


\section{Alteration in immune gene expression after infection with BmCPV}

Genes belonging to innate immunity pathways were identified and analyzed regarding their possible differential expression upon infection (Table 6). Although differences were observed, these could often not be considered as biologically important because of low expression levels (RPKMs). However, a few exceptions were noted, such as the 2-fold down-regulation of Toll6 and of one Attacin 1 homologue, as well as the 2-fold up-regulation of beta-1,3-glucan recognition protein 2 gene in pathogenically infected larvae. The expression of cecropins (A, B and E) also tended to be up-regulated during the pathogenic infection. On the other hand, Toll9-1, which was previously found to be down-regulated by exogenous dsRNA application [69], was not differentially expressed in any of the two pathogenically infected midgut samples.

\section{Detection and preliminary analysis of viral small RNAs (vsRNAs)}

Deep sequencing was also used for the analysis of the small RNAs in samples of persistently and pathogenically infected larvae. Filtering of the small RNAs for reads that map to the BmCPV genome resulted in a total of 4,487,417 reads for all 4 samples. When the number of reads of the vsRNAs was plotted against their length, a clear peak of $20 \mathrm{nt}$ vsRNAs equally distributed between both genomic dsRNA strands appeared in all 4 samples. As expected, vsRNA reads were highly abundant in pathogenically infected midguts, while for persistently infected samples their abundance was notably low. The peak of $20 \mathrm{nt}$ corresponds to 749,372 and 2,079,497 reads for the $2 \mathrm{inf}$ and $4 \mathrm{inf}$ samples, respectively, while for the control samples $2 \mathrm{c}$ and $4 c$ the small RNA counts were 324 and 481, respectively (Fig. 2).

These data clearly indicate that the RNAi machinery is responding to BmCPV infection and that the abundance of produced vsRNAs is correlated with the severity of the infection. Further analysis of the vsRNA data such as the mapping of the vsRNAs to viral dsRNA genome segments to detect hot-spots of small RNA production and to identify differences in vsRNAs between persistently and pathogenically infected animals is currently being carried out (manuscript in preparation). The observation that the vsRNAs mapped equally to sense and antisense strands of the dsRNA genome (Fig. 2) strongly indicates that the dsRNA genome segments, rather than structured dsRNA regions of viral (sense) mRNAs, are the source for production of vsRNAs by Dicer enzymes. Further studies are required to establish the functionality of the vsRNAs and to investigate whether differences in activity exist between vsRNAs produced in persistently versus pathogenically infected animals as well as between different regions of the viral dsRNA genome (cold-spots versus hot-spots).

\section{Conclusions}

In this work, the discovery of persistent BmCPV infection of our silkworm laboratory colony provided an opportunity to compare the transcriptional response to pathogenic infection with that occurring in non-persistently infected larvae, as described in the literature. Our conclusions can be summarized as follows:

1. The transcriptional response against pathogenic BmCPV infection is complex and suggests the involvement of several mechanisms, including RNAi.

2. Pre-existing persistent infection does not profoundly affect the antiviral response against pathogenic infection with the same virus, as documented by our analysis in comparison to previously reported studies.

3. Detection of vsRNAs by deep sequencing indicates the activation of the RNAi response to both persistent and pathogenic infection of BmCPV. 
Table 6. Relative RPKMs of innate immune genes.

\begin{tabular}{|c|c|c|c|c|c|c|c|c|c|}
\hline Description & Gene ID & $\begin{array}{l}\text { 2inf } \\
\text { RPKM }\end{array}$ & $\begin{array}{l}\text { 2c } \\
\text { RPKM }\end{array}$ & $\begin{array}{l}\text { 4inf } \\
\text { RPKM }\end{array}$ & $\begin{array}{l}\text { 4c } \\
\text { RPKM }\end{array}$ & $\begin{array}{l}\text { inf } \\
\text { Means }\end{array}$ & $\begin{array}{l}\text { c } \\
\text { Means }\end{array}$ & $\begin{array}{l}\text { 2inf vs } 2 c \\
\text { RPKM }\end{array}$ & $\begin{array}{l}4 \text { inf vs } 4 c \\
\text { RPKM }\end{array}$ \\
\hline \multicolumn{10}{|l|}{ Toll pathway } \\
\hline MYD88 & BGIBMGA002869 & 9.68 & 8.97 & 7.46 & 8.64 & 8.57 & 8.80 & 1.08 & 0.86 \\
\hline RelA & BGIBMGA010496 & 1.49 & 1.35 & 0.89 & 1.04 & 1.19 & 1.20 & 1.10 & 0.85 \\
\hline RelB & BGIBMGA010497 & 1.83 & 1.38 & 1.24 & 1.21 & 1.54 & 1.30 & 1.32 & 1.03 \\
\hline Toll3-1 & BGIBMGA014370 & 2.53 & 2.75 & 2.84 & 2.65 & 2.68 & 2.70 & 0.92 & 1.07 \\
\hline Toll3-2 & BGIBMGA014373 & 23.77 & 25.15 & 25.60 & 36.49 & 24.68 & 30.82 & 0.95 & 0.70 \\
\hline Toll3-2 & BGIBMGA014372 & 0.17 & 0.24 & 0.05 & 0.19 & 0.11 & 0.22 & 0.70 & 0.24 \\
\hline Toll3-3 & BGIBMGA010304 & 0.04 & 0.05 & 0.02 & 0.04 & 0.03 & 0.05 & 0.75 & 0.44 \\
\hline Toll6 & BGIBMGA011084 & 0.68 & 1.27 & 0.06 & 0.11 & 0.37 & 0.69 & 0.54 & 0.53 \\
\hline Toll7-1/7-2 & BGIBMGA011037 & 1.56 & 1.12 & 0.37 & 0.20 & 0.97 & 0.66 & 1.40 & 1.90 \\
\hline Toll7-2 & BGIBMGA011034 & 3.53 & 3.75 & 2.09 & 2.46 & 2.81 & 3.10 & 0.94 & 0.85 \\
\hline Toll7-3 & BGIBMGA011038 & 0.64 & 0.32 & 0.00 & 0.02 & 0.32 & 0.17 & 1.98 & 0.00 \\
\hline Toll8 & BGIBMGA011085 & 1.25 & 0.77 & 1.31 & 1.18 & 1.28 & 0.97 & 1.63 & 1.12 \\
\hline Toll9-1 & BGIBMGA011216 & 17.21 & 16.50 & 20.90 & 30.49 & 19.05 & 23.49 & 1.04 & 0.69 \\
\hline Toll9-2 & BGIBMGA008840 & 0.53 & 0.55 & 0.44 & 1.25 & 0.48 & 0.90 & 0.96 & 0.35 \\
\hline Toll10-2 & BGIBMGA011025 & 1.85 & 2.28 & 0.50 & 0.28 & 1.17 & 1.28 & 0.81 & 1.75 \\
\hline Toll10-3 & BGIBMGA011082 & 6.02 & 6.30 & 2.76 & 1.38 & 4.39 & 3.84 & 0.96 & 2.00 \\
\hline Toll12 & BGIBMGA006244 & 0.81 & 0.96 & 0.29 & 0.10 & 0.55 & 0.53 & 0.84 & 2.96 \\
\hline Tube & BGIBMGA002494 & 11.09 & 10.93 & 8.48 & 9.71 & 9.78 & 10.32 & 1.01 & 0.87 \\
\hline \multicolumn{10}{|l|}{ Imd pathway } \\
\hline Ikk $\beta$ & BGIBMGA008389 & 21.76 & 22.15 & 15.64 & 18.38 & 18.70 & 20.26 & 0.98 & 0.85 \\
\hline Imd & BGIBMGA003655 & 2.42 & 2.30 & 1.75 & 2.20 & 2.08 & 2.25 & 1.05 & 0.79 \\
\hline Relish1 & BGIBMGA002465 & 6.44 & 5.83 & 4.27 & 4.10 & 5.36 & 4.97 & 1.10 & 1.04 \\
\hline Relish1 & BGIBMGA002464 & 1.16 & 1.31 & 3.01 & 3.74 & 2.08 & 2.53 & 0.88 & 0.80 \\
\hline Tak1 & BGIBMGA008980 & 7.20 & 6.79 & 4.51 & 5.21 & 5.86 & 6.00 & 1.06 & 0.87 \\
\hline \multicolumn{10}{|l|}{ PPO pathway } \\
\hline $\begin{array}{l}\text { Prophenoloxidase activating } \\
\text { enzyme }\end{array}$ & BGIBMGA013746 & 0.25 & 0.12 & 0.17 & 0.39 & 0.21 & 0.26 & 2.11 & 0.44 \\
\hline Serine protease inhibitor & BGIBMGA009047 & 11.71 & 11.48 & 32.27 & 27.01 & 21.99 & 19.25 & 1.02 & 1.19 \\
\hline Serine protease inhibitor 6 & BGIBMGA007729 & 1.57 & 1.52 & 1.03 & 0.48 & 1.30 & 1.00 & 1.03 & 2.16 \\
\hline \multicolumn{10}{|l|}{ Pattern recognition receptor } \\
\hline C-type lectin 10 & BGIBMGA006768 & 1.40 & 2.27 & 0.25 & 0.12 & 0.83 & 1.19 & 0.62 & 2.14 \\
\hline C-type lectin 21 & BGIBMGA002288 & 0.23 & 0.29 & 0.23 & 0.11 & 0.23 & 0.20 & 0.79 & 2.14 \\
\hline $\begin{array}{l}\text { Beta-1,3-glucan recognition } \\
\text { protein } 2\end{array}$ & BGIBMGA011609 & 3.28 & 1.72 & 1.26 & 0.46 & 2.27 & 1.09 & 1.91 & 2.74 \\
\hline $\begin{array}{l}\text { Peptidoglycan recognition } \\
\text { protein (PGRP-L2) }\end{array}$ & BGIBMGA000584 & 2.92 & 2.67 & 1.81 & 2.58 & 2.36 & 2.63 & 1.09 & 0.70 \\
\hline $\begin{array}{l}\text { Peptidoglycan recognition } \\
\text { protein S6 }\end{array}$ & BGIBMGA012866 & 0.52 & 0.29 & 0.38 & 0.29 & 0.45 & 0.29 & 1.83 & 1.32 \\
\hline \multicolumn{10}{|l|}{ Antimicrobial peptide } \\
\hline Attacin1 & BGIBMGA002739 & 0.72 & 0.19 & 0.27 & 0.00 & 0.50 & 0.10 & 3.77 & na \\
\hline Attacin1 & BGIBMGA002747 & 0.86 & 2.29 & 0.14 & 0.31 & 0.50 & 1.30 & 0.38 & 0.44 \\
\hline
\end{tabular}


Table 6. (Continued)

\begin{tabular}{|c|c|c|c|c|c|c|c|c|c|}
\hline Description & Gene ID & $\begin{array}{l}\text { 2inf } \\
\text { RPKM }\end{array}$ & $\begin{array}{l}\text { 2c } \\
\text { RPKM }\end{array}$ & $\begin{array}{l}\text { 4inf } \\
\text { RPKM }\end{array}$ & $\begin{array}{l}\text { 4c } \\
\text { RPKM }\end{array}$ & $\begin{array}{l}\text { inf } \\
\text { Means }\end{array}$ & $\begin{array}{l}\text { c } \\
\text { Means }\end{array}$ & $\begin{array}{l}\text { 2inf vs 2c } \\
\text { RPKM }\end{array}$ & $\begin{array}{l}\text { 4inf vs } 4 c \\
\text { RPKM }\end{array}$ \\
\hline \multirow[t]{6}{*}{ CecropinA, CecropinB } & BGIBMGA000024 & 0.22 & 0.22 & 0.11 & 0.00 & 0.16 & 0.11 & 1.00 & na \\
\hline & BGIBMGA000036 & 1.18 & 0.78 & 0.00 & 0.00 & 0.59 & 0.39 & 1.51 & na \\
\hline & BGIBMGA000037 & 6.12 & 3.54 & 0.00 & 0.00 & 3.06 & 1.77 & 1.73 & na \\
\hline & BGIBMGA000021 & 23.38 & 8.49 & 0.00 & 0.00 & 11.69 & 4.24 & 2.75 & na \\
\hline & BGIBMGA000038 & 2.15 & 0.78 & 0.00 & 0.00 & 1.07 & 0.39 & 2.76 & na \\
\hline & BGIBMGA000023 & 0.00 & 0.52 & 0.00 & 0.00 & 0.00 & 0.26 & 0.00 & na \\
\hline CecropinA, CecropinE & BGIBMGA006280 & 3.16 & 1.90 & 2.45 & 0.22 & 2.80 & 1.06 & 1.67 & 11.18 \\
\hline Defensin & BGIBMGA014360 & 0.00 & 0.16 & 0.08 & 0.11 & 0.04 & 0.14 & 0.00 & 0.66 \\
\hline \multirow[t]{3}{*}{ Gloverin } & BGIBMGA013866 & 0.00 & 0.32 & 0.00 & 0.00 & 0.00 & 0.16 & 0.00 & na \\
\hline & BGIBMGA013864 & 5.89 & 5.69 & 5.98 & 7.29 & 5.94 & 6.49 & 1.04 & 0.82 \\
\hline & BGIBMGA013863 & 0.17 & 0.37 & 0.21 & 0.19 & 0.19 & 0.28 & 0.46 & 1.10 \\
\hline Gloverin 2 & BGIBMGA005658 & 1.52 & 1.53 & 12.97 & 8.28 & 7.25 & 4.91 & 0.99 & 1.57 \\
\hline Gloverin 3 & BGIBMGA013803 & 0.06 & 0.08 & 0.17 & 0.13 & 0.11 & 0.10 & 0.75 & 1.32 \\
\hline Gloverin 4 & BGIBMGA013865 & 0.16 & 0.14 & 0.05 & 0.11 & 0.10 & 0.13 & 1.13 & 0.44 \\
\hline Hemolin & BGIBMGA008736 & 0.11 & 0.44 & 0.22 & 0.31 & 0.16 & 0.37 & 0.26 & 0.69 \\
\hline Lebocin $1 / 2 / 3 / 4$ & BGIBMGA006775 & 0.22 & 1.15 & 1.24 & 0.79 & 0.73 & 0.97 & 0.19 & 1.58 \\
\hline Lysozyme & BGIBMGA007458 & 0.63 & 0.66 & 0.17 & 0.43 & 0.40 & 0.55 & 0.95 & 0.39 \\
\hline Moricin & BGIBMGA011495 & 0.67 & 0.44 & 0.11 & 0.33 & 0.39 & 0.39 & 1.51 & 0.33 \\
\hline \multicolumn{10}{|l|}{ JAK/STAT pathway } \\
\hline STAT & BGIBMGA001739 & 4.04 & 3.35 & 4.10 & 4.36 & 4.07 & 3.86 & 1.21 & 0.94 \\
\hline
\end{tabular}

Ratios of RPKM values from pathogenically versus persistently infected midgut tissue of $2^{\text {nd }}$ and $4^{\text {th }}$ instar larvae obtained by deep sequencing analysis (2c, 2inf, 4c and 4inf samples) are presented for selected genes involved in innate immunity pathways. Listed are genes belonging to Toll, Imd, PPO and JAK/STAT pathways, as well as genes encoding pattern recognition receptors and antimicrobial peptides. Genes presenting higher than 1.5-fold up- or down-regulation are marked with bold letters. Abbreviation: na: not applicable.

\section{Supporting Information}

S1 Dataset. Expression data of all genes detected in the database obtained from deep sequencing of persistently and pathogenically infected midgut tissue of $2^{\text {nd }}$ and $4^{\text {th }}$ instar larvae (2c, 2inf, 4c and 4inf libraries). Shown are RPKMs for each gene in each individual library (after trimming), as well as their average RPKMs in persistently and pathogenically infected samples. Total (not normalized) reads for each gene are also shown. The last two columns show the differential expression in pathogenically versus persistently infected midgut tissue for $2^{\text {nd }}$ and $4^{\text {th }}$ instar developmental stages.

(XLSX)

S2 Dataset. Expression data of all genes that are differentially expressed following pathogenic infection in at least one of the two library pairs obtained by deep sequencing $(2 \mathrm{c} / 2 \mathrm{inf}$ and $4 \mathrm{c} / 4 \mathrm{inf}$ pairs, corresponding to persistent/pathogenic infection at $2^{\text {nd }}$ and $4^{\text {th }}$ instar stages). Shown are RPKMs for each gene in each individual library (after trimming), as well as their average RPKMs in persistently and pathogenically infected samples. Total (not normalized) reads for each gene are also shown. The last two columns show the differential expression in pathogenically versus persistently infected midgut tissue for $2^{\text {nd }}$ and $4^{\text {th }}$ instar developmental stages.

(XLSX) 
S3 Dataset. Expression data of the $\mathbf{3 0 8}$ genes that are differentially expressed following pathogenic infection in both library pairs obtained by deep sequencing $(2 \mathrm{c} / 2 \mathrm{inf}$ and $4 \mathrm{c} / 4 \mathrm{inf}$ pairs, corresponding to persistent/pathogenic infection at $2^{\text {nd }}$ and $4^{\text {th }}$ instar stages). Shown are RPKMs for each gene in each individual library (after trimming), as well as their average RPKMs in persistently and pathogenically infected samples. Total (not normalized) reads for each gene are also shown. The last two columns show the differential expression in pathogenically versus persistently infected midgut tissue for $2^{\text {nd }}$ and $4^{\text {th }}$ instar developmental stages. Criteria for the selection of genes are described in detail in Materials and Methods section. (XLSX)

S1 Fig. Bombyx mori larvae persistently and pathogenically infected with BmCPV. Larvae of Daizo strain were orally infected with a high dose of BmCPV polyhedra at the $2^{\text {nd }}$ or the $4^{\text {th }}$ instar stage, or left untreated. The images show larvae 20 days (for $2^{\text {nd }}$ instar stage; $2 c, 2 \mathrm{inf}$ ) or 14 days (for $4^{\text {th }}$ instar stage; 4c, 4inf) after manipulation. Untreated larvae of the Daizo strain were persistently infected with BmCPV.

(TIF)

S2 Fig. Detection of BmCPV polyhedra in pathogenically infected larvae. Cubic crystalline structures (viral polyhedra) were observed under the microscope in (a) midgut tissue, (b) body wall tissue and (c) hemolymph. Magnification factor: 40x.

S3 Fig. Distribution of GO terms among highly differentially expressed genes in pathogenically infected larvae. All genes from S3 Dataset (corresponding to Fig. 2) having a GO annotation were categorized using GO tools in different classes representing biological process, molecular function and cellular component. Classification is shown at several levels of GO analysis.

S4 Fig. Relative expression levels of selected genes from pathogenically infected midguts as determined by qRT-PCR. Expression of genes showing by deep sequencing significant levels of up-regulation during pathogenic infection was validated by qRT-PCR in midgut samples of persistently and pathogenically infected $2^{\text {nd }}$ instar larvae. The graphs depict mean values of expression normalized to the housekeeping gene actin 3 , as measured for two biological and two technical replicates (+SE). For clarity, four different graphs (a-d) of relative mRNA levels are shown, in which genes with similar mRNA levels are grouped (see different scales in the graphs). High error bars obtained for expression of genes may reflect differences between samples in exact developmental stage or progression of viral infection. Expression of genes may be more strictly developmentally regulated or be more sensitive to progression of viral infection. See Table 2 for further explanation on gene identity and function.

S5 Fig. The uncharacterized protein LOC101735726. Indicated are the conserved domains PIF1 and RecD as detected by the DELTA-BLAST algorithm. PIF1-like helicase domains are implicated in the regulation of telomerase activity during the cell cycle. RecD-like helicase domains are associated with functions in DNA replication, recombination and repair.

S6 Fig. Relative expression levels of RNAi-related genes in pathogenically infected midguts as determined by qRT-PCR. Expression of several RNAi-related genes was analyzed by qRT-PCR in midgut samples of persistently and pathogenically infected $2^{\text {nd }}$ instar larvae. The graphs depict mean values of expression normalized to the housekeeping gene actin 3 , as 
measured for two biological and two technical replicates (+SE). For clarity, four different graphs (a-d) of relative mRNA levels are shown, in which genes with similar mRNA levels are grouped (see different scales in the graphs). High error bars obtained for expression of genes may reflect differences between samples in exact developmental stage or progression of viral infection. Expression of genes may be more strictly developmentally regulated or more sensitive to progression of viral infection. See Table 6 and [64] for further explanation on gene identity and function.

(TIF)

S1 Table. Sequences of primers used in qRT-PCR reactions for mRNA expression quantification. Genes are identified by their SilkDB ID (www.silkdb.org) and their GenBank Accession Number (www.ncbi.nlm.nih.gov/).

(DOCX)

\section{Acknowledgments}

Thanks are due to Dr. H. Mori (Kyoto Institute of Technology, Japan) for the generous gift of purified BmCPV polyhedra that were used in this study. We also thank Dr. A. Kohl (Institute of Infection, Immunity and Inflammation, UK) and Dr. A. Zografidis (Institute of Biosciences and Applications, NCSR "Demokritos") for useful advice regarding the analysis of the small RNAs.

\section{Author Contributions}

Conceived and designed the experiments: AK FVN DJS DD LS GS. Performed the experiments: AK FVN. Analyzed the data: AK FVN. Contributed reagents/materials/analysis tools: FVN DD LS GS. Wrote the paper: AK FVN DJS LS GS.

\section{References}

1. Hunter W, Ellis J, Vanengelsdorp D, Hayes J, Westervelt D, Glick E, et al. Large-scale field application of RNAi technology reducing Israeli acute paralysis virus disease in honey bees (Apis mellifera, Hymenoptera: Apidae). PLoS Pathog. 2010; 6(12):e1001160. Epub 2011/01/05. doi: 10.1371/journal.ppat. 1001160 PMID: 21203478

2. Subbaiah EV, Royer C, Kanginakudru S, Satyavathi VV, Babu AS, Sivaprasad V, et al. Engineering silkworms for resistance to baculovirus through multigene RNA interference. Genetics. 2013; 193 (1):63-75. Epub 2012/10/30. doi: 10.1534/genetics.112.144402 PMID: 23105011

3. Moscardi F. Assessment of the application of baculoviruses for control of Lepidoptera. Annu Rev Entomol. 1999; 44:257-89. Epub 2004/03/12. PMID: 15012374

4. Ciota AT, Kramer LD. Vector-virus interactions and transmission dynamics of West Nile virus. Viruses. 2013; 5(12):3021-47. Epub 2013/12/20. doi: 10.3390/v5123021 PMID: 24351794

5. Myles KM, Wiley MR, Morazzani EM, Adelman ZN. Alphavirus-derived small RNAs modulate pathogenesis in disease vector mosquitoes. Proc Natl Acad Sci U S A. 2008; 105(50):19938-43. Epub 2008/ 12/03. doi: 10.1073/pnas.0803408105 PMID: 19047642

6. Wu Q, Luo Y, Lu R, Lau N, Lai EC, Li WX, et al. Virus discovery by deep sequencing and assembly of virus-derived small silencing RNAs. Proc Natl Acad Sci U S A. 2010; 107(4):1606-11. Epub 2010/01/ 19. doi: 10.1073/pnas.0911353107 PMID: 20080648

7. Liu S, Vijayendran D, Bonning BC. Next generation sequencing technologies for insect virus discovery. Viruses. 2011; 3(10):1849-69. Epub 2011/11/10. doi: 10.3390/v3101849 PMID: 22069519

8. Goic B, Saleh MC. Living with the enemy: viral persistent infections from a friendly viewpoint. Curr Opin Microbiol. 2012; 15(4):531-7. Epub 2012/07/10. doi: 10.1016/j.mib.2012.06.002 PMID: 22770658

9. Villarreal LP. Viral ancestors of antiviral systems. Viruses. 2011; 3(10):1933-58. Epub 2011/11/10. doi: 10.3390/v3101933 PMID: 22069523 
10. Blair CD. Mosquito RNAi is the major innate immune pathway controlling arbovirus infection and transmission. Future Microbiol. 2011; 6(3):265-77. Epub 2011/04/01. doi: 10.2217/fmb.11.11 PMID: 21449839

11. Simon-Delso N, San Martin G, Bruneau E, Minsart LA, Mouret C, Hautier L. Honeybee colony disorder in crop areas: the role of pesticides and viruses. PLoS One. 2014; 9(7):e103073. Epub 2014/07/23. doi: 10.1371/journal.pone.0103073 PMID: 25048715

12. Niu J, Meeus I, Cappelle K, Piot N, Smagghe G. The immune response of the small interfering RNA pathway in the defense against bee viruses. Curr Opin Insect Sci. 2014; 3:1-6. PMID: 25401083

13. Mori H, Metcalf P. Cypoviruses. In: Asgari S, Johnson KN, editors. Insect Virology: Horizon Scientific Press; 2010. p. 307-23.

14. Hill CL, Booth TF, Stuart DI, Mertens PP. Lipofectin increases the specific activity of cypovirus particles for cultured insect cells. J Virol Methods. 1999; 78(1-2):177-89. Epub 1999/04/16. PMID: 10204709

15. Gao K, Deng XY, Qian HY, Qin G, Guo XJ. Digital Gene Expression analysis in the midgut of 4008 silkworm strain infected with cytoplasmic polyhedrosis virus. J Invertebr Pathol. 2014; 115:8-13. Epub 2013/11/12. doi: 10.1016/j.jip.2013.10.016 PMID: 24211674

16. Gao K, Deng XY, Qian HY, Qin GX, Hou CX, Guo XJ. Cytoplasmic polyhedrosis virus-induced differential gene expression in two silkworm strains of different susceptibility. Gene. 2014; 539(2):230-7. Epub 2014/02/15. doi: 10.1016/j.gene.2014.01.073 PMID: 24525400

17. Wu P, Li M, Wang X, Zhao P, Wang X, Liu T, et al. Differentially expressed genes in the midgut of silkworm infected with cytoplasmic polyhedrosis virus. Afr J Biotechnol. 2009; 8(16):3711-20.

18. Wu P, Wang X, Qin GX, Liu T, Jiang YF, Li MW, et al. Microarray analysis of the gene expression profile in the midgut of silkworm infected with cytoplasmic polyhedrosis virus. Mol Biol Rep. 2011; 38(1):33341. Epub 2010/03/30. doi: 10.1007/s11033-010-0112-4 PMID: 20349281

19. Wu P, Han S, Chen T, Qin G, Li L, Guo X. Involvement of microRNAs in infection of silkworm with bombyx mori cytoplasmic polyhedrosis virus (BmCPV). PLoS One. 2013; 8(7):e68209. Epub 2013/07/12. doi: 10.1371/journal.pone.0068209 PMID: 23844171

20. Kingsolver MB, Huang Z, Hardy RW. Insect antiviral innate immunity: pathways, effectors, and connections. J Mol Biol. 2013; 425(24):4921-36. Epub 2013/10/15. doi: 10.1016/j.jmb.2013.10.006 PMID: 24120681

21. Bronkhorst AW, van Rij RP. The long and short of antiviral defense: small RNA-based immunity in insects. Curr Opin Virol. 2014; 7C:19-28. Epub 2014/04/16.

22. Nayak $A$, Tassetto $M$, Kunitomi $M$, Andino R. RNA interference-mediated intrinsic antiviral immunity in invertebrates. Curr Top Microbiol Immunol. 2013; 371:183-200. Epub 2013/05/21. doi: 10.1007/978-3642-37765-5_7 PMID: 23686236

23. Shimomura $M$, Minami $H$, Suetsugu $Y$, Ohyanagi $H$, Satoh $C$, Antonio $B$, et al. KAlKObase: an integrated silkworm genome database and data mining tool. BMC Genomics. 2009; 10:486. Epub 2009/10/22. doi: 10.1186/1471-2164-10-486 PMID: 19843344

24. Mortazavi A, Williams BA, McCue K, Schaeffer L, Wold B. Mapping and quantifying mammalian transcriptomes by RNA-Seq. Nat Methods. 2008; 5(7):621-8. Epub 2008/06/03. doi: 10.1038/nmeth.1226 PMID: 18516045

25. Zhang F, Guo Z, Zhong H, Wang S, Yang W, Liu Y. RNA-Seq-based transcriptome analysis of aflatoxigenic Aspergillus flavus in response to water activity. Toxins (Basel). 2014; 6(11):3187-207. Epub 2014/11/26. doi: 10.3390/toxins6113187 PMID: 25421810

26. Chevignon G, Cambier S, Da Silva C, Poulain J, Drezen JM, Huguet E, et al. Transcriptomic response of Manduca sexta immune tissues to parasitization by the bracovirus associated wasp Cotesia congregata. Insect Biochem Mol Biol. 2015. Epub 2015/01/15.

27. Gu J, Huang LX, Gong YJ, Zheng SC, Liu L, Huang LH, et al. De novo characterization of transcriptome and gene expression dynamics in epidermis during the larval-pupal metamorphosis of common cutworm. Insect Biochem Mol Biol. 2013; 43(9):794-808. Epub 2013/06/26. doi: 10.1016/j.ibmb.2013.06. 001 PMID: 23796435

28. Core Team R. R: a language and environment for statistical computing. R Foundation for Statistical Computing, Vienna, Austria. 2012.

29. Carbon S, Ireland A, Mungall CJ, Shu S, Marshall B, Lewis S. AmiGO: online access to ontology and annotation data. Bioinformatics. 2009; 25(2):288-9. Epub 2008/11/27. doi: 10.1093/bioinformatics/ btn615 PMID: 19033274

30. Huang da W, Sherman BT, Lempicki RA. Systematic and integrative analysis of large gene lists using DAVID bioinformatics resources. Nat Protoc. 2009; 4(1):44-57. Epub 2009/01/10. doi: 10.1038/nprot. 2008.211 PMID: 19131956 
31. Liang J, Zhang L, Xiang Z, He N. Expression profile of cuticular genes of silkworm, Bombyx mori. BMC Genomics. 2010; 11:173. Epub 2010/03/17. doi: 10.1186/1471-2164-11-173 PMID: 20226095

32. Ruan W, Xu E, Xu F, Ma Y, Deng H, Huang Q, et al. IGFBP7 plays a potential tumor suppressor role in colorectal carcinogenesis. Cancer Biol Ther. 2007; 6(3):354-9. Epub 2007/02/22. PMID: 17312390

33. Ruan WJ, Lin J, Xu EP, Xu FY, Ma Y, Deng H, et al. IGFBP7 plays a potential tumor suppressor role against colorectal carcinogenesis with its expression associated with DNA hypomethylation of exon 1. J Zhejiang Univ Sci B. 2006; 7(11):929-32. Epub 2006/10/19. PMID: 17048309

34. Wajapeyee N, Serra RW, Zhu X, Mahalingam M, Green MR. Oncogenic BRAF induces senescence and apoptosis through pathways mediated by the secreted protein IGFBP7. Cell. 2008; 132(3):363-74. Epub 2008/02/13. doi: 10.1016/j.cell.2007.12.032 PMID: 18267069

35. Chen Y, Cui T, Knosel T, Yang L, Zoller K, Petersen I. IGFBP7 is a p53 target gene inactivated in human lung cancer by DNA hypermethylation. Lung Cancer. 2011; 73(1):38-44. Epub 2010/11/26. doi: 10.1016/j.lungcan.2010.10.015 PMID: 21095038

36. Chen $\mathrm{Y}$, Pacyna-Gengelbach $\mathrm{M}, \mathrm{Ye} F$, Knosel $\mathrm{T}$, Lund $\mathrm{P}$, Deutschmann N, et al. Insulin-like growth factor binding protein-related protein 1 (IGFBP-rP1) has potential tumour-suppressive activity in human lung cancer. J Pathol. 2007; 211(4):431-8. Epub 2007/01/20. PMID: 17236181

37. Gao K, Deng XY, Qian HY, Wu P, Qin GX, Liu T, et al. Novel protein of IBP from silkworm, Bombyx mori, involved in cytoplasmic polyhedrosis virus infection. J Invertebr Pathol. 2012; 110(1):83-91. Epub 2012/03/10. doi: 10.1016/j.jip.2012.02.011 PMID: 22401767

38. Chen CS, Bellier A, Kao CY, Yang YL, Chen HD, Los FC, et al. WWP-1 is a novel modulator of the DAF-2 insulin-like signaling network involved in pore-forming toxin cellular defenses in Caenorhabditis elegans. PLoS One. 2010; 5(3):e9494. Epub 2010/03/09. doi: 10.1371/journal.pone.0009494 PMID: 20209166

39. Xu J, Hopkins K, Sabin L, Yasunaga A, Subramanian H, Lamborn I, et al. ERK signaling couples nutrient status to antiviral defense in the insect gut. Proc Natl Acad Sci U S A. 2013; 110(37):15025-30. Epub 2013/08/28. doi: 10.1073/pnas.1303193110 PMID: 23980175

40. Girardin SE, Philpott DJ. PGRP-LB minds the fort. Immunity. 2006; 24(4):363-6. Epub 2006/04/19. PMID: 16618594

41. Zaidman-Remy A, Herve M, Poidevin M, Pili-Floury S, Kim MS, Blanot D, et al. The Drosophila amidase PGRP-LB modulates the immune response to bacterial infection. Immunity. 2006; 24(4):463-73. Epub 2006/04/19. PMID: 16618604

42. Tyler KL, Clarke P, DeBiasi RL, Kominsky D, Poggioli GJ. Reoviruses and the host cell. Trends Microbiol. 2001; 9(11):560-4. Epub 2002/02/05. PMID: 11825717

43. Kominsky DJ, Bickel RJ, Tyler KL. Reovirus-induced apoptosis requires mitochondrial release of Smac/DIABLO and involves reduction of cellular inhibitor of apoptosis protein levels. J Virol. 2002; 76 (22):11414-24. Epub 2002/10/22. PMID: 12388702

44. Kominsky DJ, Bickel RJ, Tyler KL. Reovirus-induced apoptosis requires both death receptor- and mitochondrial-mediated caspase-dependent pathways of cell death. Cell Death Differ. 2002; 9(9):926-33. Epub 2002/08/16. PMID: 12181743

45. Stewart ME, Roy P. Role of cellular caspases, nuclear factor-kappa $B$ and interferon regulatory factors in Bluetongue virus infection and cell fate. Virol J. 2010; 7:362. Epub 2010/12/08. doi: 10.1186/1743422X-7-362 PMID: 21134281

46. Lavazec C, Boudin C, Lacroix R, Bonnet S, Diop A, Thiberge S, et al. Carboxypeptidases B of Anopheles gambiae as targets for a Plasmodium falciparum transmission-blocking vaccine. Infect Immun. 2007; 75(4):1635-42. Epub 2007/02/07. PMID: 17283100

47. Ponnuvel KM, Nithya K, Sirigineedi S, Awasthi AK, Yamakawa M. In vitro antiviral activity of an alkaline trypsin from the digestive juice of Bombyx mori larvae against nucleopolyhedrovirus. Arch Insect Biochem Physiol. 2012; 81(2):90-104. Epub 2012/08/18. doi: 10.1002/arch.21046 PMID: 22898997

48. Bao YY, Li MW, Zhao YP, Ge JQ, Wang CS, Huang YP, et al. Differentially expressed genes in resistant and susceptible Bombyx mori strains infected with a densonucleosis virus. Insect Biochem Mol Biol. 2008; 38(9):853-61. Epub 2008/08/06. doi: 10.1016/j.ibmb.2008.06.004 PMID: 18678256

49. Molina-Cruz A, Gupta L, Richardson J, Bennett K, Black Wt, Barillas-Mury C. Effect of mosquito midgut trypsin activity on dengue-2 virus infection and dissemination in Aedes aegypti. Am J Trop Med Hyg. 2005; 72(5):631-7. Epub 2005/05/14. PMID: 15891140

50. Sanglas L, Aviles FX, Huber R, Gomis-Ruth FX, Arolas JL. Mammalian metallopeptidase inhibition at the defense barrier of Ascaris parasite. Proc Natl Acad Sci U S A. 2009; 106(6):1743-7. Epub 2009/01/ 31. doi: 10.1073/pnas.0812623106 PMID: 19179285

51. Giuliano JS, Lahni PM, Wong HR, Wheeler DS. Extracellular Heat Shock Proteins: Alarmins for the Host Immune System. The Open Inflammation Journal. 2011; 4(Suppl1-M6):49-60. 
52. Li ZW, Li X, Yu QY, Xiang ZH, Kishino H, Zhang Z. The small heat shock protein (sHSP) genes in the silkworm, Bombyx mori, and comparative analysis with other insect sHSP genes. BMC Evol Biol. 2009; 9:215. Epub 2009/09/01. doi: 10.1186/1471-2148-9-215 PMID: 19715580

53. Iwanaga M, Shibano Y, Ohsawa T, Fujita T, Katsuma S, Kawasaki H. Involvement of HSC70-4 and other inducible HSPs in Bombyx mori nucleopolyhedrovirus infection. Virus Res. 2013. Epub 2013/11/ 12.

54. Sagisaka A, Fujita K, Nakamura Y, Ishibashi J, Noda H, Imanishi S, et al. Genome-wide analysis of host gene expression in the silkworm cells infected with Bombyx mori nucleopolyhedrovirus. Virus Res. 2010; 147(2):166-75. Epub 2009/11/04. doi: 10.1016/j.virusres.2009.10.015 PMID: 19883703

55. Liu J, Bai J, Zhang L, Jiang Z, Wang X, Li Y, et al. Hsp70 positively regulates porcine circovirus type 2 replication in vitro. Virology. 2013; 447(1-2):52-62. Epub 2013/11/12. doi: 10.1016/j.virol.2013.09.021 PMID: 24210126

56. Li L, Sevinsky JR, Rowland MD, Bundy JL, Stephenson JL, Sherry B. Proteomic analysis reveals virusspecific Hsp25 modulation in cardiac myocytes. J Proteome Res. 2010; 9(5):2460-71. Epub 2010/03/ 04. doi: 10.1021/pr901151k PMID: 20196617

57. Smith JA, Schmechel SC, Raghavan A, Abelson M, Reilly C, Katze MG, et al. Reovirus induces and benefits from an integrated cellular stress response. J Virol. 2006; 80(4):2019-33. Epub 2006/01/28. PMID: 16439558

58. Lee SK, Son le T, Choi HJ, Ahnn J. Dicarbonyl//-xylulose reductase (DCXR): The multifunctional pentosuria enzyme. Int J Biochem Cell Biol. 2013; 45(11):2563-7. Epub 2013/08/31. doi: 10.1016/j.biocel. 2013.08.010 PMID: 23988570

59. Son le T, Ko KM, Cho JH, Singaravelu G, Chatterjee I, Choi TW, et al. DHS-21, a dicarbonyl/L-xylulose reductase (DCXR) ortholog, regulates longevity and reproduction in Caenorhabditis elegans. FEBS Lett. 2011; 585(9):1310-6. Epub 2011/04/12. doi: 10.1016/j.febslet.2011.03.062 PMID: 21477590

60. Field LM, Devonshire AL. Evidence that the E4 and FE4 esterase genes responsible for insecticide resistance in the aphid Myzus persicae (Sulzer) are part of a gene family. Biochem J. 1998;330 (Pt 1: ):16973. Epub 1998/04/16.

61. Altstein M, Nassel DR. Neuropeptide signaling in insects. Adv Exp Med Biol. 2010; 692:155-65. Epub 2010/12/31. PMID: 21189678

62. Gan L, Liu X, Xiang Z, He N. Microarray-based gene expression profiles of silkworm brains. BMC Neurosci. 2011; 12:8. Epub 2011/01/21. doi: 10.1186/1471-2202-12-8 PMID: 21247463

63. Vodovar N, Saleh MC. Of insects and viruses: The role of small RNAs in insect defence. In: Jockusch EL, editor. Small RNAs Their Diversity, Roles and Practical uses: Academic Press; 2012. p. 1-36.

64. Swevers L, Huvenne H, Menschaert G, Kontogiannatos D, Kourti A, Pauchet Y, et al. Colorado potato beetle (Coleoptera) gut transcriptome analysis: expression of RNA interference-related genes. Insect Mol Biol. 2013; 22(6):668-84. doi: 10.1111/imb.12054 PMID: 24580832

65. Kolliopoulou A, Swevers L. Functional analysis of the RNAi response in ovary-derived silkmoth Bm5 cells. Insect Biochem Mol Biol. 2013; 43(8):654-63. Epub 2013/05/15. doi: 10.1016/j.ibmb.2013.05. 001 PMID: 23669468

66. Zhu L, Tatsuke T, Mon H, Li Z, Xu J, Lee JM, et al. Characterization of Tudor-sn-containing granules in the silkworm, Bombyx mori. Insect Biochem Mol Biol. 2013; 43(8):664-74. Epub 2013/05/07. doi: 10. 1016/j.ibmb.2013.04.004 PMID: 23643815

67. Izumi N, Kawaoka S, Yasuhara S, Suzuki Y, Sugano S, Katsuma S, et al. Hsp90 facilitates accurate loading of precursor piRNAs into PIWI proteins. RNA. 2013; 19(7):896-901. Epub 2013/05/18. doi: 10. 1261/rna.037200.112 PMID: 23681506

68. Xiol J, Cora E, Koglgruber R, Chuma S, Subramanian S, Hosokawa M, et al. A role for Fkbp6 and the chaperone machinery in piRNA amplification and transposon silencing. Mol Cell. 2012; 47(6):970-9. Epub 2012/08/21. doi: 10.1016/j.molcel.2012.07.019 PMID: 22902560

69. Liu J, Smagghe G, Swevers L. Transcriptional response of BmToll9-1 and RNAi machinery genes to exogenous dsRNA in the midgut of Bombyx mori. J Insect Physiol. 2013; 59(6):646-54. Epub 2013/04/ 23. doi: 10.1016/j.jinsphys.2013.03.013 PMID: 23602829 